\title{
Slow recoveries: any role for corporate leverage?*
}

\author{
FRANK SMETS $^{\dagger}$ Stefania VILlA ${ }^{\ddagger}$
}

June 28, 2016

\begin{abstract}
This paper examines whether financial conditions of the non-financial corporate sector can explain why the recovery from recessions in the United States is slower since the mid-1980s. Leverage by the corporate sector has increased significantly since the financial deregulation of the mid-1980s. Empirical evidence shows that slow recoveries are associated with a significant drop in the growth rates of investment and bank loans, and with a surge in the growth rates of corporate bonds. In an estimated dynamic stochastic general equilibrium model with a financial accelerator, counterfactual experiments based on estimates of two samples - 1965-1983 and 19842007 - show that the non-financial corporate indebtedness affects only marginally the speed of the recovery in the two samples.
\end{abstract}

Keywords: speed of recoveries, indebtedness, financial frictions, estimated DSGE model.

JEL Codes: E32, E44

\section{Introduction}

In recent times there has been an increasing interest on the role of leverage and indebtedness in shaping the business cycle. Leverage that builds up in 'normal times' can generate adverse feedback loops in 'bad times', eventually leading to a prolonged credit crunch (Brunnermeier et al., 2012). Changes in balance sheets of borrowers and lenders can substantially affect the response of macroeconomic variables to adverse shocks hitting the economy. $\mathrm{Ng}$ and Wright (2013) argue that the process of deleveraging can affect the recovery. In fact, in a highly leveraged economy the whole private sector - financial institutions, firms and households - attempt to deleverage when asset prices start to fall. Since all agents increase saving at the same time the economy looses demand, thereby frustrating any attempt to repair balance sheets. In a sample of 14 advanced countries between 1870 and 2008, Jordà et al. (2013) find evidence of a close relationship between credit-intensive expansions and the intensity and the persistence of the subsequent recession.

\footnotetext{
${ }^{*}$ We are grateful to two anonymous referees, Julio Carrillo, Ferre De Graeve, Ester Faia, Vivien Lewis, Giovanni Melina, Karel Mertens, Raf Wouters and to seminar participants at the Belgian Macroeconomics Workshop, University of Hamburg, City University London, University of Surrey for useful comments and suggestions. The usual disclaimer applies. We acknowledge financial support from the EU FP7-Project MACFINROBODS, grant no. 612796. The views expressed here should not be attributed to the European Central Bank or the Eurosystem.

${ }^{\dagger}$ European Central Bank, 60640 Frankfurt am Main, Germany; and Center for Economic Studies, KU Leuven, Naamsestraat 69, 3000 Leuven, Belgium. Tel.: +49 691344 0; Fax: +49 691344 6000. E-mail: Frank.Smets@ecb.int.

${ }^{\ddagger}$ Center for Economic Studies, KU Leuven, Naamsestraat 69, 3000 Leuven, Belgium; and Department of Economics, University of Foggia, 71100 Foggia, Italy. Tel.: +39 0881753713; Fax: +39 0881781771. E-mail: stefania.villa@unifg.it.
} 
Recovery rates from recessions - computed as four and eight-quarter growth after trough - have become significantly slower since the mid-1980s in the US economy, as shown by Galí et al. (2012) in the context of the debate jobless versus slow recoveries. At the same time, financial deregulation has led to an increase in leverage in many sectors of the US economy.

This paper investigates whether the build-up of leverage in the non-financial corporate sector could help explain the slow recoveries. The key intuition is that, because of the deleveraging process in response to shocks, borrowers may postpone investment because they have to build up their capital. The paper first documents three sets of stylised facts in the US economy. First, following Galí et al. (2012) it shows that in the post-WWII period the speed of recovery of economic activity following recessions has significantly slowed down since the mid-1980s. Differently from Galí et al. (2012), the paper examines the growth rates of the GDP main components and it shows that these slower recoveries are associated with a large and significant drop in the growth rate of (in particular non-residential) investment following a recession. The cumulated growth rate of non-residential investment two years after the trough of the recession falls from more than $16 \%$ in the earlier period to less than $2 \%$ after the mid-1980s. This drop in the growth rate of investment is also reflected in a significant drop of borrowing by the non-financial corporate sector. While before the mid-1980s, real debt of the corporate sector typically grew by more than 10 percent in the two years after the trough of a recession, afterwards real debt remained below its level at the trough of the recession for two years following the trough. Second, in the the non-financial corporate sector the growth rates of loans are significantly slower since the mid-1980s, while the contrary happens for the growth rates of corporate bonds. Third, following the financial deregulation of the mid-1980s leverage of the corporate sector, defined as the ratio of total assets over net worth, has increased quite strongly. Average leverage rose from 1.6 in the period from 1965Q1 to 1983Q4 to a level of more than 1.9 in the period from 1984Q1 to 2007Q4. In other words, the debt to equity ratio of the corporate sector rose by 50 percent. Data also show that while there was a significant increase in business default rates, the external finance premium has not risen that much during the Great Moderation.

The paper then uses an estimated New Keynesian (NK) model with a financial accelerator à la Bernanke et al. (1999) to examine whether the slow recoveries from the 1990s could be explained by the different financial conditions of the corporate sector. The mechanism in the model works as follows: changes in borrowers' balance sheets affect investment decisions, and hence output. In the phase of a recession, the private sector is reducing debt, asset prices fall while liabilities remain. The business sector is forced to repair balance sheets by increasing savings or paying down debt. This act of deleveraging reduces aggregate demand and lead the economy into a recession. To investigate the extent to which changes in borrowers balance sheet affect the recovery, in a first step, we estimate the NK model over two samples, 1965Q1-1983Q4 and 1984Q1-2007Q4, setting corporate leverage, spreads and business failure rates to those values observed in the data. ${ }^{1}$ In a second step, similarly to Galí et al. (2012), we conduct counterfactual experiments in order to examine whether financial

\footnotetext{
${ }^{1}$ Other papers have estimated a similar model for the US/Euro Area economy with different research questions (see De Graeve, 2008; von Heideken, 2009; Gelain, 2010; Del Negro and Schorfheide, 2013; Christiano et al., 2014; Fuentes-Albero, 2014; Villa, 2016, among others).
} 
factors might explain the difference in the speed of recoveries. Galí et al. (2012), instead, examine first the role of shocks - while keeping parameters unchanged - and then the role of all the structural parameters in explaining the slower recoveries in a dynamic stochastic general equilibrium (DSGE) model à la Smets and Wouters (2007) also featuring unemployment. In a third step we analyse the sensitivity of the impulse response functions (IRFs) to different financial conditions of the nonfinancial corporate sector. Our main finding is that financial factors account only very partially for the evidence of slow recoveries from the mid-1980s.

The closest study to ours is Fuentes-Albero (2014), who investigates whether a similar DSGE model - estimated for the US economy with structural breaks in a subset of the parameter space - is able to the capture the large volatility in financial aggregates contemporary with the low volatility in real and nominal variables during the Great Moderation.

The remainder of the paper is structured as follows. Section 2 presents the stylised facts regarding changes in the speed of recoveries and financial conditions of the corporate business sector since the mid-1980s. Section 3 briefly sketches the NK model. Section 4 presents the counterfactual exercises and impulse response function analysis. Finally, Section 5 briefly concludes. The appendix complements the paper by providing (a) basic evidence on the indebtedness of the household sector and of all commercial banks in the US economy; (b) the derivation of the financial contract, the deterministic steady state and the full set of the DSGE model linearised equilibrium conditions; (c) steady state effects of changing the deep financial parameters of the model; (d) details on the construction of the dataset used in the estimation; and (e) a series of robustness checks for the results.

\section{A preliminary look at the data}

This section analyses the speed of recovery following a recession of some macroeconomic variables as well as developments in the non-financial corporate sector in the US economy in the post-WWII era.

Similarly to Galí et al. (2012), Figure 1 shows growth rates accumulated over four and eight quarters following each postwar U.S. recession of real output, real personal consumption expenditures, and real fixed private investment. ${ }^{2}$ The figure confirms that the speed of recovery of GDP has slowed down from the 1990s. A similar slowdown can be seen in the cumulated growth rates of investment and consumption, although growth rates of investment show a more pronounced pattern, mainly due to its higher volatility compared to consumption. Table 1 reports the average growth rates after NBER recessions of GDP and its main components in the pre-90 sample, which considers 8 recessions, and in the 3 recessions of the post-90 sample. It is evident that the average speed of recoveries of these variables is statistically different across the two samples.

Figure 2 disentangles the growth rate of total investment into its two components, residential and non-residential fixed investment. Although growth rates of residential investment are generally

\footnotetext{
${ }^{2}$ Appendix A reports all data sources and transformations. Data on 8-quarter growth do not include the recession in 1980 because of potential overlaps with the 1982 recession.
} 
higher than those of non-residential investment, both series show lower growth rates after trough from the 1990s. This is also reflected in the tests of statistical difference. While for non-residential investment we always reject the null hypothesis of equal mean of the growth rates pre- and post1990 at a significance level below one percent, for the series of residential investment we cannot reject the null hypothesis of equal mean of the 8-quarter growth rate after trough across the two subsamples. As evident from the chart, the 8-quarter growth after trough of residential investment has considerably decreased in the recent financial crisis, but not in the previous two recessions.

Now we first discuss developments of leverage and indebtedness of the non-financial business sector. Then we compute growth rates after trough of various measures of indebtedness. We finally present some evidence on default rates and spreads. Financial data on the US non-financial corporate sector have extensively been discussed in the literature (Geanakoplos, 2010; Covas and Den Haan, 2011; Jermann and Quadrini, 2012, among many others). The left chart of Figure 3 shows an increasing trend of leverage, defined as the ratio between total assets and net worth, over the period 1951Q4-2011Q4. The right chart of Figure 3 shows another measure of leverage, defined as the ratio between tangible assets and net worth (defined as tangible assets minus credit market liabilities). This latter measure is consistent with the DSGE model presented in the following sections. Both charts show an increasing trend of leverage during the Great Moderation and a remarkable deleveraging after the dot-com bubble followed by a rapid surge before the financial crisis - particularly evident for the second definition of leverage.

Table 2 reports some indicators of indebtedness of the non-financial corporate business sector for the whole sample, for the sample 1965Q1-2007Q4, and the two subsamples, 1965Q1-1983Q4 and 1984Q1-2007Q4. The leverage of the corporate business sector ranges from 1.59 over 1965Q11983Q4 to 1.93 during the Great Moderation. A similar picture also holds for the other measure of leverage, which is equal to 1.40 in the 1965Q1-1983Q4 sample and it rises to 1.77 during the Great Moderation.

Figure 4 presents growth rates accumulated over 4-quarter and 8-quarter following each postwar U.S. recession of real credit market instruments of the non-financial corporate business sector. With the exception of the 1975 crisis, the corporate sector tends to postpone its borrowing in the last three recessions. This is also confirmed in Table 1, which reports a significant change in the speed of recovery of real credit market instruments. The table also shows that the change in the growth rates pre- and post-1990 of total liabilities is statistically significant at 5\%.

In the US financial system bond markets represent the predominant way of supplying funds (Allen et al., 2004). Corporate bonds account for almost $50 \%$ of total credit instruments of the non-financial corporate business sector in the post-WWII era, while depository institution loans account for less than $25 \%$ as shown in Table 2. Figure 5 shows the 4 -quarter and 8-quarter growth rates after trough of real corporate bonds. Differently from the previous findings, in this case it is not possible to detect a difference in the growth rates in the latest three recessions. As evident from Table 1, both the 4-quarter and 8-quarter growth rates after trough are even higher since the 1990s, 


\begin{tabular}{|c|c|c|c|c|c|c|}
\hline & \multicolumn{4}{|c|}{ 4-quarter growth } & \multicolumn{2}{|c|}{ 8-quarter growth } \\
\hline & Pre-90 & Post-90 & Change & Pre-90 & Post-90 & Change \\
\hline GDP & 7.63 & 2.62 & $5.01^{* * *}$ & 12.52 & 5.64 & $6.87^{* * *}$ \\
\hline Consumption & 5.19 & 2.76 & $2.43^{* *}$ & 9.60 & 6.01 & $3.59^{* * *}$ \\
\hline Investment & 12.96 & -1.32 & $14.28^{* * *}$ & 19.02 & 5.10 & $13.91^{* * *}$ \\
\hline Residential investment & 24.18 & 7.49 & $16.69^{*}$ & 28.80 & 14.02 & 14.79 \\
\hline Non-residential investment & 8.56 & -4.45 & $13.01^{* * *}$ & 16.62 & 1.43 & $15.19^{* * *}$ \\
\hline \multicolumn{7}{|l|}{ Non-financial corporate sector } \\
\hline Total liabilities & 5.23 & 1.02 & $4.20^{* *}$ & 11.76 & 0.69 & $11.07^{* * *}$ \\
\hline Credit market instruments & 3.61 & -2.35 & $5.96^{* * *}$ & 10.64 & -1.22 & $11.87^{* *}$ \\
\hline Corporate bonds & 3.43 & 4.79 & -1.37 & 8.05 & 11.39 & $-3.34^{*}$ \\
\hline Depository institut. loans & 1.76 & -15.05 & $16.81^{* * *}$ & 10.47 & -20.85 & $31.32^{* * *}$ \\
\hline \multicolumn{7}{|c|}{ Non-financial corporate and non-corporate sector } \\
\hline Total liabilities & 5.57 & 0.39 & $5.18^{* * *}$ & 13.53 & -2.34 & $15.87^{* * *}$ \\
\hline Credit market instruments & 4.71 & -2.33 & $7.04^{* * *}$ & 7.79 & -1.36 & $9.15^{*}$ \\
\hline \multicolumn{7}{|l|}{ Household sector } \\
\hline Liabilities (home mortgages) & 6.24 & 3.92 & 2.32 & 15.88 & 8.12 & 7.76 \\
\hline
\end{tabular}

Table 1: Speed of recoveries (in percent) in the two subsamples

and the difference of the 8 -quarter speed of recovery is statistically significant at $10 \%$ level. $^{3}$

Figure 6 shows growth rates accumulated over 4-quarter and 8-quarter following each postwar U.S. recession of real depository institution loans. It is evident that the lower growth rates of credit market instruments in the latest three recessions are driven by the developments of depository institution loans. The difference in both the 4-quarter and 8-quarter growth rates of bank loans is statistically significant as shown in Table 1. Growth rates of loans can be explained by the change in bank lending standards. Figure 7 shows the net percentage of domestic banks tightening standards for commercial and industrial loans to large and middle-market firms from 1967Q1 to 2014Q1 (Lown and Morgan, 2006). The negative growth rates of depository institutions loans, shown in Figure 6, occur indeed in correspondence with tighter standards in 1974Q1, 1991Q1, 2001Q4 and 2009Q2.

We finally report some data on the non-financial business sector which are used in the next sections: default rates and corporate spreads. Annual data on default rates are shown in Figure 8. Data show a clear counter-cyclical pattern; this is particularly evident in the last three recessions. Average default rates at the time of the recessions in the Great Moderation are much higher than the

\footnotetext{
${ }^{3}$ In this case we perform a left-tailed t-test, i.e. the mean of the first period is less than that of the second period. It is worth noting that small and large firms obtain funds from different sources: the former rely primarily on bank credit to finance their investments, while the latter obtain a considerable portion of funding in direct markets (Gertler and Gilchrist, 1993).
} 


\begin{tabular}{|c|c|c|c|c|}
\hline & $\begin{array}{c}\text { 1951Q4- } \\
\text { 2011Q4 }\end{array}$ & $\begin{array}{c}\text { 1965Q1- } \\
2007 \mathrm{Q} 4\end{array}$ & $\begin{array}{c}\text { 1965Q1- } \\
1983 \mathrm{Q} 4\end{array}$ & $\begin{array}{c}\text { 1984Q1- } \\
\text { 2007Q4 }\end{array}$ \\
\hline Corporate bonds/credit market liabilities & 0.48 & 0.46 & 0.44 & 0.47 \\
\hline Dep. inst. loans/credit market liabilities & 0.22 & 0.22 & 0.26 & 0.19 \\
\hline Leverage: Total assets/ net worth & 1.70 & 1.78 & 1.59 & 1.93 \\
\hline $\begin{array}{l}\text { Leverage: tangible assets/ (tangible } \\
\text { assets-credit market instruments) }\end{array}$ & 1.58 & 1.61 & 1.40 & 1.77 \\
\hline Annual default rates* & 3.23 & 3.10 & 1.62 & 3.90 \\
\hline
\end{tabular}

* The series starts in 1971. Sources: Flow of Funds Accounts and Altman and Kuehne (2012)

Table 2: Indicators of indebtedness of the non-financial corporate business sector over different samples and annual default rates.

\begin{tabular}{lcccc}
\hline & 1951Q4- & 1965Q1- & 1965Q1- & 1984Q1- \\
& $2011 \mathrm{Q} 4$ & $2007 \mathrm{Q} 4$ & $1983 \mathrm{Q} 4$ & 2007Q4 \\
\hline Moody's Baa - Aaa & 97 & 102 & 113 & 94 \\
Moody's Aaa - 10Year Treasury constant maturity* $^{*}$ & 84 & 89 & 61 & 111 \\
Moody's Baa - 10Year Treasury constant maturity* & 182 & 191 & 173 & 205 \\
Spread by Gilchrist and Zakrajsek (2012)* & 145 & 141 & 98 & 160 \\
\hline
\end{tabular}

* The series of 10-year Treasury constant maturity rate starts in 1953q2.

** This measure starts in 1973Q1 and ends in 2010q3.

Source: ALFRED database St. Louis Fed and Gilchrist and Zakrajsek (2012)

Table 3: Time series of the spread (basis points)

corresponding values in the period 1971-1983. The mean annual default rate is less than 2 percent during the 1971-1983 sample, and it increases to almost 4 percent during the Great Moderation.

In order to provide some information on the cost of borrowing, we present some proxies of the external finance premium, i.e. the spread over the "risk-free rate". Table 3 reports the following measures of the spread: (i) the difference in yields between the lowest-rated (Moody's Baa) and highest-rated (Moody's Aaa) investment-grade corporate bonds; (ii) the Moody's Aaa Corporate Bond Yield spread over the 10-Year Treasury Yield at Constant Maturity (CM); Moody's Baa Corporate Bond Yield spread over the 10-Year Treasury Yield at CM; and (iv) the series of the spread constructed by Gilchrist and Zakrajšek (2012), based on prices of individual corporate bonds traded in the secondary market. In the subsample 1984Q1-2007Q4 the spread is generally higher, but for Moody's Baa minus Aaa. Figure 9 shows the series of the spread reported in the table in the period 1965Q1-2012Q1. ${ }^{4}$ With the exception of the recent financial crisis it is not possible to detect any increasing trend in the different measures of spread.

\footnotetext{
${ }^{4}$ The series by Gilchrist and Zakrajšek (2012) starts in 1973Q1 and ends in 2010Q3.
} 


\section{The DSGE model}

This section briefly sketches a standard DSGE model with real and nominal frictions as in Smets and Wouters (2007), which also features a financial accelerator mechanism à la Bernanke et al. (1999) (BGG). The BGG model has been chosen for a variety of reasons. First, the seminal contribution by BGG is an important reference point in the mainstream DSGE literature on financial frictions. Second, this model might address issues related to the financial conditions of the non-financial business sector. Third it captures some of the mechanisms through which credit market conditions can impact macroeconomic dynamics (see also Christiano et al., 2014): the firms balance sheet channel is present, while the household balance sheet channel and the bank lending channel are absent. The former channel stresses the importance of balance sheet conditions of debtors: when borrowers have little wealth to contribute to the project financing, the potential divergence of interests between borrowers and lenders (the suppliers of external funds) is greater and, therefore, agency costs increase. In equilibrium lenders must be compensated for higher agency costs by a larger external finance premium, i.e. the difference between the cost of raising funds externally and the opportunity cost of using internal finance. Therefore, the external finance premium depends inversely on borrowers' net worth. Fluctuations in borrowers' balance sheets due to changes in asset prices and cash flow then affect investment decisions and, hence, output. ${ }^{5}$

The economy is populated by: households; labor unions; labor packers; retailers; final good firms; capital producers; entrepreneurs; and the policymaker. Households consume, save, and supply labor. A labor union differentiates labor and sets wages in a monopolistically competitive market. Competitive labor packers buy labor service from the union, package and sell it to entrepreneurs. In the goods market retailers buy goods from intermediate goods firms, differentiate them and sell them in a monopolistically competitive market. The aggregate final good is produced by perfectly competitive firms assembling a continuum of intermediate goods. Capital producers purchase investment and depreciated capital to transform them into capital sold to entrepreneurs and used for production. Entrepreneurs maximize the flow of discounted profits by choosing the quantity of factors for production and stipulate a financial contract to obtain funds from lenders. For the financing decision there is a costly state verification problem (Townsend, 1979) and lenders might have to pay a fixed auditing cost to observe an individual borrower's return. The policymaker sets the nominal interest rate following a Taylor rule. Since the structure of model closely follows Smets and Wouters (2007) and BGG, here we discuss those features needed to understand the following sections. The system of all the linearized equilibrium conditions is shown in Appendix B.2.

\footnotetext{
${ }^{5}$ Alternatively, we could have investigated the bank lending channel, which focuses on the supply of intermediate credit, in a model à la Gertler and Karadi (2011). However, in such a model an economy with more leveraged banks can lend more compared to an economy with less leveraged banks. The model by Gertler and Karadi in fact requires that the incentive compatibility constraint (between households and banks) is always satisfied; and, at any reasonable calibrated level of indebtedness, banks can still afford to lend. Hence, such a model is not a good candidate to answer the research question of the paper.
} 
The representative household maximizes the utility function, which specializes as

$$
U_{t}(\cdot)=\frac{\left(C_{t}-h C_{t-1}\right)^{1-\sigma^{c}}}{1-\sigma^{c}} \exp \left(\frac{\sigma^{c}-1}{1+\sigma^{\ell}}\left(L_{t}^{h}\right)^{1+\sigma^{\ell}}\right)
$$

where $h$ measures the degree of superficial external habits in consumption, $\sigma^{c}$ is the parameter of relative risk aversion, $L_{t}^{h}$ is labour supply in terms of hours worked and $\sigma^{\ell}$ measures the elasticity of labour supply with respect to the real wage. The representative household enters period $t$ with nominal deposits in the banks, that pay the gross nominal interest rate, $R_{t}^{n}$, between $t$ and $t+1$. During period $t$, each household chooses to consume $C_{t}$; supplies $L_{t}^{h}$ hours of work; and allocates savings in deposits, $D_{t}$. Each household gains an hourly real wage, and dividend payments from firms. The government grants transfers and imposes real lump-sum taxes.

Households supply homogeneous labour to monopolistic labour unions which differentiate it. Labour service used by entrepreneurs is a composite of differentiated types of labour. As in Kimball (1985) the price elasticity of demand is a function of relative prices. Labour unions adjust wages infrequently following the Calvo scheme. Let $\sigma_{w}$ be the probability of keeping wages constant; hence, each period there is a constant probability $\left(1-\sigma_{w}\right)$ that the union is able to adjust the wage, independently of past history. For the other fraction that cannot adjust, the wage is automatically increased at the aggregate inflation rate, where $\sigma_{w i}$ denotes the degree of wage indexation. The goods market has a similar structure: retailers purchase intermediate goods at a price equal to the marginal cost and differentiate them in a monopolistically competitive market. Each retailer resets its price with probability $\left(1-\sigma_{p}\right)$ and $\sigma_{p i}$ denotes the degree of price indexation.

Capital producers purchase at time $t$ investment and depreciated capital to transform them into capital sold to firms and used for production at time $t+1$. The law of motion of capital is then equal to

$$
K_{t+1}=(1-\delta) K_{t}+x_{t}\left[1-\digamma\left(\frac{I_{t}}{I_{t-1}}\right)\right] I_{t}
$$

where $\delta$ stands for depreciation. The adjustment cost function $\digamma$ satisfies the following properties: $\digamma(1)=\digamma^{\prime}(1)=0$, and $\digamma^{\prime \prime}(1)=\xi>0$. The shock to the marginal efficiency of investment, $x_{t}$, follows an $\operatorname{AR}(1)$ process, $\rho_{x}$ is an autoregressive coefficient and $\varepsilon_{t}^{x}$ is a serially uncorrelated, normally distributed shock with zero mean and standard deviation $\sigma_{x}$. Profits are given by the difference between the revenue from selling capital at the relative price $Q_{t}$ and the costs of buying capital from intermediate goods firms and the investment needed to build new capital. The optimality condition is a Tobin's $Q$ equation, which relates the price of capital to the marginal adjustment costs.

Entrepreneurs produce goods in a perfectly competitive market. They maximize the flow of discounted profits by choosing the quantity of factors for production. The production function specializes as

$$
Y_{t}=A_{t}\left(\tilde{K}_{t}\right)^{\alpha}\left(L_{t}\right)^{1-\alpha}
$$

where $\tilde{K}=U_{t} K_{t}, U_{t}$ is the utilization rate and $L_{t}=\left(L_{t}^{h}\right)^{\Omega}\left(L_{t}^{e}\right)^{1-\Omega}$. $L_{t}^{e}$ is entrepreneurial labor which, for simplicity, is equal to 1 . $A_{t}$ is the transitory productivity (TFP) shock following an $\operatorname{AR}(1)$ 
process, $\rho_{a}$ is an autoregressive coefficient and $\varepsilon_{t}^{a}$ is a serially uncorrelated, normally distributed shock with zero mean and standard deviation $\sigma_{a}$. The real gross aggregate ex-post return on capital expenditures, $R_{t+1}^{k}$, is equal to

$$
E_{t}\left[R_{t+1}^{k}\right]=E_{t}\left[\frac{Z_{t+1}^{k}+(1-\delta) Q_{t+1}}{Q_{t}}\right]
$$

where $Z_{t}^{k}$ is the real rental price of capital, given by

$$
Z_{t}^{k}=\alpha M C_{t} \frac{Y_{t}}{\tilde{K}_{t}}
$$

At the end of period $t$, entrepreneurs buy from capital producers capital, $K_{t+1}$, that will be used at time $t+1$ at the real price $Q_{t}$. Capital purchases are financed by internal and external financing. The former is given by net worth, $N_{t+1}$ - net worth at the end of time $t$ - and the latter by borrowing from banks, $B_{t+1}$. In equilibrium total loans supplied to the entrepreneurs are equal to households deposits, i.e. $B_{t}=D_{t}$. The amount of borrowing is defined as

$$
B_{t+1}=Q_{t} K_{t+1}-N_{t+1}
$$

The return to capital is sensitive to an idiosyncratic shock. The ex post gross return on capital for entrepreneur $j$ is $\omega_{t}^{j} R_{t+1}^{k}$, where $\omega_{t}^{j}$ is an idiosyncratic disturbance to entrepreneur $j$ return. ${ }^{6}$ The disturbance is an i.i.d. log-normal variable with standard deviation $\sigma, \ln (\omega) \sim N\left(-0.5 \sigma^{2}, \sigma^{2}\right)$. Then $E[\omega]=1$ and

$$
E[\omega \mid \omega \geq \bar{\omega}]=\frac{1-\Phi^{N}(z-\sigma)}{1-\Phi^{N}(z)}
$$

where $\Phi^{N}(\cdot)$ is the cumulative distribution function $(\mathrm{CDF})$ of the standard normal and $z \equiv(\ln (\bar{\omega})+$ $\left.0.5 \sigma^{2}\right) / \sigma$.

After the investment decision is made, the lender can observe $\omega$ only by paying the monitoring cost, which is a proportion $\mu$ of the realized gross payoff to the firm's capital, i.e. $\mu \omega_{t+1} R_{t+1}^{k} Q_{t} K_{t+1}$. The optimal financial contract specifies a cutoff value for the idiosyncratic shock, $\bar{\omega}$, such that if $\omega \geq \bar{\omega}$ the entrepreneur is able to repay the loan at the contractual rate $R_{t}^{l}$. Alternatively, if $\omega \leq \bar{\omega}$ the borrower gets nothing, the lender pays the auditing costs and his net receipts are $(1-\mu) \omega_{t+1} R_{t+1}^{k} Q_{t} K_{t+1}$. The threshold value, $\bar{\omega}$, is defined as follows

$$
\bar{\omega}_{t+1} R_{t+1}^{k} Q_{t} K_{t+1}=R_{t}^{l} B_{t+1}
$$

Hence, if $\omega \geq \bar{\omega}$, the entrepreneur repays the lender the amount $R_{t}^{l} B_{t+1}$ and keeps the difference equal to $\omega_{t+1} R_{t+1}^{k} Q_{t} K_{t+1}-R_{t}^{l} B_{t+1}$. The entrepreneur offers a state-contingent contract that guarantees the lender an expected return equal to the riskless rate. The expected gross share of profits going

\footnotetext{
${ }^{6}$ For the sake of simplicity we drop the $j$ index. For aggregation see BGG.
} 
to the lender is defined as follows

$$
\Gamma\left(\bar{\omega}_{t+1}\right)=\int_{0}^{\bar{\omega}_{t+1}} \omega f(\omega) d \omega+\bar{\omega}_{t} \int_{\bar{\omega}_{t+1}}^{\infty} f(\omega) d \omega
$$

and $\Gamma^{\prime}(\bar{\omega})=1-F(\bar{\omega})$, where $F(\bar{\omega})$ is the business failure rate. ${ }^{7}$

The financial contract is chosen to maximise entrepreneurial utility subject to the participation constraint for the lender:

$$
\begin{array}{ll}
\max & \left(1-\Gamma\left(\bar{\omega}_{t}\right)\right) R_{t}^{k} Q_{t-1} K_{t} \\
\text { s.t. } & {\left[\Gamma\left(\bar{\omega}_{t}\right)-\mu G\left(\bar{\omega}_{t}\right)\right] R_{t}^{k} Q_{t-1} K_{t}=R_{t-1}\left(Q_{t-1} K_{t}-N_{t}\right)}
\end{array}
$$

where the net share of profits going to the lender is $\Gamma\left(\bar{\omega}_{t}\right)-\mu G\left(\bar{\omega}_{t}\right)$, the gross share is $\Gamma\left(\bar{\omega}_{t}\right)$ and $\Gamma^{\prime \prime}(\bar{\omega})=-f(\bar{\omega})$. The monitoring costs are defined as $\mu G\left(\bar{\omega}_{t}\right)=\mu \int_{0}^{\bar{\omega}_{t}} \omega f(\omega) d \omega$ and $G^{\prime}\left(\bar{\omega}_{t}\right)=\bar{\omega}_{t} f(\bar{\omega})$. The constraint, equation (10), assures that the return to lend to entrepreneurs, left hand side, should be equal to the opportunity costs of lending, right hand side, where $R_{t-1}$ is the gross real interest rate implied by the loan contract signed at time $t-1$. Appendix $\mathrm{F}$ investigates the robustness of the results in the case of nominal debt-contracts.

Let $s=\frac{R^{k}}{R}, k=\frac{Q K}{N}$ (the leverage ratio), and $\lambda$ the Lagrange multiplier. The first order conditions are:

$$
\begin{aligned}
\bar{\omega}: & \Gamma^{\prime}\left(\bar{\omega}_{t}\right)-\lambda_{t}\left[\Gamma^{\prime}\left(\bar{\omega}_{t}\right)-\mu G^{\prime}\left(\bar{\omega}_{t}\right)\right]=0 \\
k: & \left\{\left(1-\Gamma\left(\bar{\omega}_{t}\right)\right)+\lambda_{t}\left[\Gamma\left(\bar{\omega}_{t+1}\right)-\mu G\left(\bar{\omega}_{t}\right)\right]\right\} s_{t}-\lambda_{t}=0 \\
\lambda: & {\left[\Gamma\left(\bar{\omega}_{t}\right)-\mu G\left(\bar{\omega}_{t}\right)\right] s_{t} k_{t}-\left(k_{t}-1\right)=0 }
\end{aligned}
$$

As shown in Appendix B.1, the spread can be expressed as a function of the leverage ratio. In particular, the spread between the external financing cost and the real interest rate can be written as

$$
E\left[\frac{R_{t+1}^{k}}{R_{t}}\right]=E P\left(\frac{N_{t+1}}{Q_{t} K_{t+1}}\right) b_{t}
$$

where $E P$, the external finance premium, has the following properties: $E P^{\prime}(\cdot)<0, E P^{\prime}(1)=1$; and $b_{t}$ is a risk premium shock as in Del Negro and Schorfheide (2013). As the borrower's equity stake in a project $N_{t+1} / Q_{t} K_{t+1}$ falls, i.e. the leverage ratio rises, the loan becomes riskier and the cost of borrowing rises.

In order to ensure that entrepreneurial net worth will never be enough to fully finance capital acquisitions, it is assumed that each entrepreneur survives until the next period with probability $\theta$ and her expected lifetime is consequently equal to $1 /(1-\theta)$. Net worth is given by the sum of the entrepreneurial equity, $V_{t}$, and what is earned by entrepreneurial labour in the production of goods,

$$
N_{t+1}=\theta V_{t} \varepsilon_{t}^{n}+W_{t}^{e}
$$

\footnotetext{
${ }^{7}$ The time index is dropped for briefness.
} 
where $\varepsilon_{t}^{n}$ is a wealth shock similarly to Fuentes-Albero (2014) and Mumtaz and Zanetti (2016).

Entrepreneurial equity is given by the difference between earning on assets and borrowing repayments, including the monitoring costs

$$
V_{t}=R_{t}^{k} Q_{t-1} K_{t}-\left(R_{t-1}+\frac{\mu G\left(\omega_{t}\right) R_{t}^{k} Q_{t-1} K_{t}}{Q_{t-1} K_{t}-N_{t}}\right)\left(Q_{t-1} K_{t}-N_{t}\right)
$$

The entrepreneurs that die consume the residual net worth. Entrepreneurial consumption is then equal to

$$
C_{t}^{e}=(1-\theta) V_{t}
$$

The policymaker sets the nominal interest rate according to the following Taylor rule

$$
\frac{R_{t}^{n}}{R^{n}}=\left(\frac{R_{t-1}^{n}}{R^{n}}\right)^{\rho_{i}}\left[\left(\frac{\Pi_{t}}{\Pi}\right)^{\rho_{\pi}}\left(\frac{Y_{t}}{Y_{t}^{*}}\right)^{\rho_{y}}\right]^{1-\rho_{i}}\left(\frac{Y_{t} / Y_{t}^{*}}{Y_{t-1} / Y_{t-1}^{*}}\right)^{\rho_{\Delta y}} \varepsilon_{t}^{i}
$$

where $Y_{t}^{*}$ is the level of output that would prevail under flexible prices and wages without the two mark-up shocks, and $\varepsilon_{t}^{i}$ is the monetary policy shock. The resource constraint completes the model:

$$
Y_{t}=C_{t}+I_{t}+G_{t}+\Psi\left(U_{t}\right) K_{t-1}+\mu G\left(\bar{\omega}_{t}\right) R_{t}^{k} Q_{t-1} K_{t}
$$

There are eight orthogonal structural shocks: the risk premium, the investment-specific technology, the wealth, the monetary policy, the government, the TFP, the price mark-up, and the wage mark-up shocks. The following linearized equilibrium conditions related to the financial accelerator mechanism can explain how the firms balance sheet channel is operational in the model: ${ }^{8}$

$$
E\left[\hat{R}_{t+1}^{k}\right]-\hat{R}_{t}=\varkappa\left(\hat{Q}_{t}+\hat{k}_{t+1}-\hat{n}_{t+1}\right)+\hat{b}_{t}
$$

Equation (20) states that the external financing cost must equate the external finance premium, gross of the real interest rate, $\hat{R}_{t}=\hat{R}_{t}^{n}-\hat{\Pi}_{t+1}$. The external finance premium depends positively on the leverage, $\hat{Q}_{t}+\hat{k}_{t+1}-\hat{n}_{t+1}$. The parameter $\varkappa \equiv-\frac{\partial E P}{\partial \frac{N}{K}} \frac{N / K}{E P}=-\frac{E P^{\prime}(\cdot)}{R^{k}} \frac{N}{K} R$ measures the elasticity of the external finance premium with respect to the leverage position of entrepreneurs and it depends on the value of the idiosyncratic shock $\bar{\omega}$. This equation captures the effects of borrowers' balance sheets on the cost of external finance.

The evolution of net worth, equation (21), mainly depends on entrepreneurial equity of surviving entrepreneurs:

$$
\hat{n}_{t+1}=\frac{\theta}{\gamma} \frac{V}{N} \hat{v}_{t}+\frac{W^{e}}{\gamma N} \hat{w}_{t}^{e}+e_{t}^{n}
$$

The role of wage income is indeed very small, given that under most calibrations, the fraction of entrepreneurial labour is 0.01 . The ratio of wage income to net worth, $W^{e} / N$, is about 0.001 , while the ratio of entrepreneurial equity to net worth, $V / N$, is greater than one. ${ }^{9}$ The survival rate, $\theta$,

\footnotetext{
${ }^{8}$ Lower case variables represent detrended variables, variables without time subscripts denote steady-state values, and the hat denotes variables log-linearized around their steady state balanced growth path.

${ }^{9}$ In fact some papers (e.g. Christensen and Dib, 2008) ignore entrepreneurial labour since it exerts a negligible impact on the dynamics of the model.
} 
clearly affects the persistence of net worth.

The evolution of entrepreneurial equity, equation (22), is affected by steady state values of the following financial parameters: total monitoring costs, $\mu G(\bar{\omega})$, and its derivative; the threshold value of the idiosyncratic shock, $\bar{\omega}$; the leverage ratio, $K / N$; the gross real return on capital expenditures, $R^{k}$; and the gross real nominal rate, $R$,

$$
\begin{aligned}
\frac{V}{N} \widehat{v}_{t} & =[1-\mu G(\bar{\omega})] R_{t}^{k} \frac{K}{N} \hat{R}_{t}^{k}+\frac{K}{N}\left[(1-\mu G(\bar{\omega})) R^{k}-R\right]\left(\hat{Q}_{t-1}+\hat{k}_{t}\right)- \\
& -\frac{K}{N} \mu R^{k} G^{\prime}(\bar{\omega}) \bar{\omega}_{\hat{\omega}}+R\left(\frac{K}{N}-1\right) \hat{R}_{t-1}+R \hat{n}_{t}
\end{aligned}
$$

Equity clearly depends negatively on monitoring costs and on the threshold value of the idiosyncratic shock. An increase in the steady state leverage ratio, on one hand, raises the amount of assets and, hence, their return. On the other hand, it also implies higher borrowing repayments. Higher steady state return on capital expenditures unambiguously raises entrepreneurial equity, while a change in the steady state real interest rate affects the borrowing decisions agreed in the loan contract.

The threshold value of the idiosyncratic shock is governed by the following equation:

$$
\hat{s}_{t}=[1-s[\Gamma(\bar{\omega})-\mu G(\bar{\omega})]]\left\{\frac{\Gamma^{\prime \prime}(\bar{\omega})}{\Gamma^{\prime}(\bar{\omega})}-\frac{\left[\Gamma^{\prime \prime}(\bar{\omega})-\mu G^{\prime \prime}(\bar{\omega})\right]}{\Gamma^{\prime}(\bar{\omega})-\mu G^{\prime}(\bar{\omega})}\right\} \bar{\omega} \hat{\bar{\omega}}_{t+1}
$$

The rationale of the first order condition of the financial contract is that the higher the threshold value, $\bar{\omega}$, the higher the spread, $s$.

By definition, borrowing, equation (24), depends positively on total assets and negatively on net worth,

$$
\hat{b}_{t+1}=\left(1-\frac{N}{K}\right)^{-1}\left(\hat{Q}_{t}+\hat{k}_{t+1}\right)-\left(\frac{K}{N}-1\right)^{-1} \hat{n}_{t+1}
$$

The lower the steady state leverage ratio the higher is the impact of the value of assets and net worth on the dynamics of debt.

Nonlinearities might arise from the financial accelerator mechanism, which should be stronger the deeper the economy is in recession and the weaker the balance sheet of borrowers (Bernanke et al., 1996; Mertens and Ravn, 2011). In fact, the flight to quality implies that changes in net worth induce a greater variation in the agency costs of lending for low-net-worth borrowers compared to high-net-worth borrowers. Appendix $\mathrm{C}$ investigates these nonlinearities by examining how the deep financial parameters affect steady state leverage, spread and elasticity of the external finance premium with respect to the leverage position of entrepreneurs.

\section{Results on the role of financial factors}

This section analyses the effects of financial factors in accounting for slow recoveries since the mid1980s. Section 4.1 discusses the estimation strategy. Section 4.2 presents counterfactual experiments 


\begin{tabular}{ll}
\hline Parameters & \\
\hline$\delta$, depreciation rate & 0.025 \\
$\alpha$, capital share & 0.333 \\
$\beta$, discount factor & 0.9985 \\
$\sigma^{c}$ relative risk aversion & 1.28 \\
$\Omega$, fraction of household labour & 0.99 \\
$\frac{G}{Y}$, government share of GDP & 0.18 \\
$\varepsilon^{p} / \varepsilon^{w}$, Kimball aggregator in the goods/labour market & 33 \\
\hline
\end{tabular}

Table 4: Calibrated parameters common to both samples

that investigate the role of financial factors in affecting the speed of recovery in the two estimated samples, 1965Q1-1983Q4 and 1984Q1-2007Q4. ${ }^{10}$ Section 4.3 discusses transmission mechanisms via the IRFs analysis.

\subsection{Estimation strategy}

The model is estimated with Bayesian methods over two samples, 1965Q1-1983Q4 and 1984Q12007Q4, using a set of macroeconomic and financial variables. In particular, we use the following observable eight variables: GDP, consumption, investment, wage, hours worked, GDP deflator inflation, the federal funds rate and the spread. Appendix D presents a detailed discussion of data sources, definitions and transformations. The number of variables in the data coincides with the number of shocks in the model.

Table 4 shows the calibration of the parameters - common to the two samples - that cannot be identified in the dataset and/or are related to steady state values of the variables. The time period in the model corresponds to one quarter in the data. The depreciation rate, $\delta$, is equal to 0.025 , corresponding to an annual depreciation rate of $10 \%$. The capital share, $\alpha$, is one third. The discount factor, $\beta$, and the coefficient of relative risk aversion, $\sigma^{c}$, are set equal to 0.9985 and 1.28 respectively, implying an annualised interest rate of $6.7 \%$. Similarly to BGG the fraction of household labour, $\Omega$, is calibrated at 0.99 so that the share of income going to entrepreneurial labour is small. The ratio of government spending to GDP is equal to 0.18. The Kimball aggregators in the goods and labour market are calibrated at 33, with the price and wage mark-up at 1.1 (e.g. Coenen et al., 2007).

In steady state the threshold value of the idiosyncratic shock, $\bar{\omega}$, which determines the leverage, the spread and the business failure rate, is a function of the following underlying parameters: $\delta$, $\alpha, \beta, \sigma^{c}, \Omega, \gamma, \Pi, \mu, \sigma$ and $\theta$ (equation (38) in Appendix B.1). The quarterly growth rate of real GDP, consumption, investment and wage, $\gamma$ and the steady state inflation rate are set consistently with the series in the dataset over the two samples 1965Q1-1983Q4 and 1984Q1-2007Q4, as shown in Table 5. The deep financial parameters of the model are: (i) $\mu$, the proportion of monitoring

\footnotetext{
${ }^{10}$ The dataset ends in 2007Q4 to avoid potential distortionary effects on the estimates of the zero lower bound on the nominal interest rate as in Galí et al. (2011). For the sake of robustness, Appendix E.1 shows the sensitivity of the results when the dataset include the Great Recession.
} 


\begin{tabular}{lll}
\hline Parameters & $1965 \mathrm{Q} 1-1983 \mathrm{Q} 4$ & $1984 \mathrm{Q} 4-2007 \mathrm{Q} 4$ \\
\hline$\gamma$, steady state common growth rate & 1.00427 & 1.00439 \\
$\Pi$, steady state inflation rate & 1.0143 & 1.0063 \\
$\mu$, proportion of monitoring costs & 0.245 & 0.105 \\
$\sigma$, volatility of idiosyncratic shock & 0.426 & 0.333 \\
$\theta$, survival rate of firms & 0.9762 & 0.9813 \\
\hline
\end{tabular}

Table 5: Calibration of sample-specific parameters

costs; (ii) $\sigma$, the volatility of the idiosyncratic shock; and (iii) $\theta$, the survival rate of entrepreneurs. The monitoring costs reflect the accounting and legal fees, asset liquidation, and interruption of business in the case that the entrepreneur defaults on the debt contract. Monitoring costs reflect the easiness of access to external financing (Fuentes-Albero, 2014). This parameter broadly captures the process of financial deregulation of the mid 1980s in the US economy. Levin et al. (2004) find that monitoring costs exhibits substantial temporal variation over the 1997-2003 sample; on the contrary, their estimates of the volatility of the idiosyncratic shock reveal little time variation across the entire distribution of firms. Christiano et al. (2014) define exogenous variations to the volatility of idiosyncratic uncertainty as "risk shocks". ${ }^{11}$ The introduction of survival rate in this class of models, instead, is a convenient assumption made in order to avoid full self-financing by entrepreneurs. The deep financial parameters are set to target the following steady state values for the 1965Q1-1983Q4 sample: a leverage ratio of 1.40, a spread of 173 basis points per year and an annualised business failure rate of less than two percent, in line with the data reported in Tables 2 and 3. Hence, the definition of leverage consistent with the model does not include financial assets, trade and taxes payables, and miscellaneous liabilities as in Fuentes-Albero (2014) and the proxy of the spread is the difference between Moody's Baa and 10 Year Treasury yield at constant maturity as in Del Negro and Schorfheide (2013). This translates into setting the proportion of monitoring costs equal to 0.245, the standard deviation of the idiosyncratic shock to 0.426 and the survival rate to $0.9762 .{ }^{12}$ These values imply an elasticity of the external finance premium with respect to the leverage position equal to 0.054 . The 1984Q1-2007Q4 sample is characterised by a higher leverage, spread and business failure rate, equal to 1.77, 205 basis points and about four percent per year, respectively. In order to target these values the monitoring costs are equal to 0.105. A lower value in the period of the Great Moderation captures the process of financial deregulation of the mid 1980s in the US economy. The volatility of the idiosyncratic shock is equal to 0.333 , while the survival rate is equal to 0.9813 . The corresponding value of the elasticity of the external finance premium with respect to the leverage

\footnotetext{
${ }^{11}$ They find that risk shocks play an important role in driving business cycle fluctuations. The effects of these shocks are similar to those of the risk premium shock in equation (20), since they both influence the demand for capital (by affecting the amount of credit extended to entrepreneurs).

${ }^{12}$ The deep financial parameters are calibrated because they are not well identified in the data. Several contributions compare the model by Smets and Wouters (2007) (SW) with a SW model augmented with the financial accelerator à la Bernanke et al. (1999) (see De Graeve, 2008; von Heideken, 2009; Villa, 2016, among many others). In all these contributions the comparison of marginal data densities reveals that financial frictions are empirically relevant since they improve the fit of the model. We rely on this literature because it shows that the financial accelerator model is not only accepted by the data but it also provides a gain in fitting macroeconomic variables compared to a standard SW economy.
} 


\begin{tabular}{|c|c|c|c|c|c|}
\hline & \multicolumn{3}{|c|}{ Prior distribution } & Posterior mean & Posterior mean \\
\hline Parameters & Distr & Mode & St.Dev. & $1965-1983$ & $1984-2007$ \\
\hline \multicolumn{6}{|l|}{ Structural } \\
\hline$\xi$, inv. adj. costs & Normal & 4 & 1.5 & $4.65[2.85,6.34]$ & $4.07[2.09,5.96]$ \\
\hline$\sigma^{\ell}$, elasticity of work & Normal & 2 & 0.25 & $2.18[1.81,2.56]$ & $2.42[2.06,2.77]$ \\
\hline$h$, habit parameter & Beta & 0.7 & 0.1 & $0.41[0.33,0.48]$ & $0.29[0.21,0.36]$ \\
\hline$\sigma_{p}$, Calvo prices & Beta & 0.5 & 0.1 & $0.55[0.50,0.59]$ & $0.90[0.83,0.95]$ \\
\hline$\sigma_{w}$, Calvo wages & Beta & 0.5 & 0.1 & $0.86[0.81,0.92]$ & $0.87[0.82,0.92]$ \\
\hline$\sigma_{p i}$, price indexation & Beta & 0.5 & 0.15 & $0.33[0.15,0.51]$ & $0.36[0.10,0.64]$ \\
\hline$\sigma_{w i}$, wage indexation & Beta & 0.5 & 0.15 & $0.59[0.41,0.77]$ & $0.35[0.14,0.56]$ \\
\hline$\zeta$, elasticity of capital util & Beta & 0.5 & 0.15 & $0.69[0.52,0.86]$ & $0.79[0.69,0.90]$ \\
\hline$\rho_{\pi}$, Taylor rule & Normal & 1.5 & 0.25 & $1.55[1.39,1.72]$ & $1.53[1.16,1.89]$ \\
\hline$\rho_{y}$, Taylor rule & Beta & 0.125 & 0.05 & $0.03[0.01,0.05]$ & $0.12[0.06,0.18]$ \\
\hline$\rho_{\Delta_{y}}$, Taylor rule - changes in $y$ & Normal & 0.2 & 0.05 & $0.23[0.17,0.30]$ & $0.28[0.23,0.33]$ \\
\hline$\rho_{i}$, Taylor rule smoothing & Beta & 0.75 & 0.1 & $0.51[0.45,0.56]$ & $0.81[0.76,0.85]$ \\
\hline $\bar{\ell}$, steady state hours worked & Normal & 0 & 2 & $-1.32[-3.21,0.67]$ & $0.81[-0.26,1.85]$ \\
\hline $\bar{s}$, steady state spread & Normal & 0.50 & 0.1 & $0.50[0.34,0.67]$ & $0.48[0.32,0.64]$ \\
\hline \multicolumn{6}{|l|}{ Shocks } \\
\hline$\rho_{a}$, per. of tech shock & Beta & 0.5 & 0.2 & $0.98[0.97,1.00]$ & $0.96[0.93,0.99]$ \\
\hline$\rho_{b}$, per. of risk premium shock & Beta & 0.5 & 0.2 & $0.88[0.81,0.95]$ & $0.92[0.88,0.95]$ \\
\hline$\rho_{g}$, per. of gov shock & Beta & 0.5 & 0.2 & $0.96[0.94,0.98]$ & $0.94[0.92,0.96]$ \\
\hline$\rho_{x}$, per. of investment shock & Beta & 0.5 & 0.2 & $0.55[0.39,0.71]$ & $0.58[0.49,0.67]$ \\
\hline$\rho_{i}$, per. of monetary shock & Beta & 0.5 & 0.2 & $0.15[0.05,0.24]$ & $0.19[0.08,0.30]$ \\
\hline$\rho_{p}$, per. of price mark-up shock & Beta & 0.5 & 0.2 & $0.67[0.47,0.87]$ & $0.70[0.43,0.92]$ \\
\hline$\rho_{w}$, per. of wage mark-up shock & Beta & 0.5 & 0.2 & $0.61[0.38,0.86]$ & $0.64[0.39,0.89]$ \\
\hline$\rho_{n}$, per. of wealth shock & Beta & 0.5 & 0.2 & $0.98[0.97,1.00]$ & $0.99[0.98,1.00]$ \\
\hline$\mu_{p}, \mathrm{MA}$ - price mark-up shock & Beta & 0.5 & 0.2 & $0.46[0.20,0.71]$ & $0.87[0.77,0.98]$ \\
\hline$\mu_{w}, \mathrm{MA}$ - wage mark-up shock & Beta & 0.5 & 0.2 & $0.48[0.24,0.71]$ & $0.92[0.87,0.98]$ \\
\hline$\rho_{g a}$, per. of gov to tech shock & Beta & 0.5 & 0.25 & $0.53[0.41,0.66]$ & $0.45[0.32,0.59]$ \\
\hline$\sigma_{a}$, std of tech shock & IG & 0.1 & 2 & $0.81[0.70,0.92]$ & $0.45[0.40,0.51]$ \\
\hline$\sigma_{b}$, std of risk premium shock & $\mathrm{IG}$ & 0.1 & 2 & $0.10[0.09,0.12]$ & $0.06[0.05,0.07]$ \\
\hline$\sigma_{g}$, std of gov shock & $\mathrm{IG}$ & 0.1 & 2 & $0.52[0.45,0.60]$ & $0.38[0.33,0.42]$ \\
\hline$\sigma_{x}$, std of investment shock & $\mathrm{IG}$ & 0.1 & 2 & $0.75[0.54,0.95]$ & $0.56[0.45,0.68]$ \\
\hline$\sigma_{i}$, std of monetary shock & $\mathrm{IG}$ & 0.1 & 2 & $0.43[0.36,0.50]$ & $0.13[0.11,0.15]$ \\
\hline$\sigma_{p}$, std of price mark-up shock & $\mathrm{IG}$ & 0.1 & 2 & $0.20[0.16,0.25]$ & $0.18[0.15,0.21]$ \\
\hline$\sigma_{w}$, std of wage mark-up shock & $\mathrm{IG}$ & 0.1 & 2 & $0.19[0.14,0.23]$ & $0.37[0.32,0.42]$ \\
\hline$\sigma_{n}$, std of wealth shock & $\mathrm{IG}$ & 0.1 & 2 & $0.32[0.24,0.40]$ & $0.19[0.15,0.23]$ \\
\hline
\end{tabular}

Table 6: Prior and posterior distributions in the two samples

position is equal to 0.037. As explained in Appendix C, lower monitoring costs imply that business investment becomes less sensitive to financial frictions.

Table 6 shows the posterior distributions of the remaining parameters estimated over two sample periods. For each parameter the table reports the posterior mean with $95 \%$ probability intervals in parentheses. During the Great Moderation the volatility of most shocks has decreased as evident from Figure 10, that shows the smoothed shocks which are the main drivers of output and investment. 
Some differences emerge for the structural parameters. The habit persistence parameter decreases in the second sample, while the autoregressive coefficient of the risk premium shock rises. The degree of price stickiness is higher in the second sample, wage indexation to past inflation has fallen in the second sample. Finally the second sample features a higher elasticity of capital utilization. As noted by Galí et al. (2012), it is difficult to assess whether these changes are due to weak identification or to an effective change in the economic structure.

\subsection{Counterfactual experiments}

The counterfactual experiment allows to analyse the role of the parameters in accounting for slower recoveries since mid 1980s. As a first step, for the baseline estimated models we compute the speed of recovery of the simulated series of GDP, investment, consumption and borrowing for the two samples. Sample 1 considers the four recessions from 1965Q1 to 1983Q4 (i.e. 1970Q3, 1975Q1, 1980Q2 and 1982Q3), while sample 2 takes into account the two recessions in 1991Q1 and in 2001Q4. The difference between growth rates after NBER recessions of Table 1 and of Table 7 is due to the fact that: (i) the former are coming from the data, the latter from the estimated model; (ii) the observable variables used in the model are logged and expressed in per capita terms differently from the data; and (iii) the episodes of recessions are different. As shown in Table 7, in sample 1 the speed of recovery of the logged per capita series of GDP is 3.80, that of investment is 6.93 , and that of consumption is 2.93. And they are higher than those in sample 2. The model is also able to replicate the slower recovery of non-financial corporate sector borrowing in the Great Moderation, although borrowing is not included as observable variable in the dataset. In fact, the 4-quarter growth rate of borrowing is 1.07 in the first sample and it decreases to -5.34 in the second sample.

Following Galí et al. (2012), the counterfactual experiment for sample 1 consists in simulating the model economy imposing the deep financial parameters (and all the estimated structural parameters) of sample 2, while keeping all the smoothed shocks estimated in the previous sample. In such a way it is possible to simulate the outcomes of sample 1-shocks with sample 2-parameters. We then compute the speed of recovery of GDP, investment, consumption and borrowing, i.e. the average 4-quarter growth rate after recession. Similar procedure is used to run counterfactual experiments for sample 2 .

Sample 1 features lower leverage, spread and business failure rates, equal to 1.40, 173 basis points per year and about $2 \%$ per year respectively. Sample 2 instead features a leverage of 1.77 , a spread of 205 basis points per year and a business failure rate of almost $4 \%$. In the model estimated for sample 1 the first counterfactual simulation consists in imposing the financial parameters of sample 2. The counterfactual exercise shows that there is indeed a slower recovery by changing the financial parameters: the average growth rate of GDP is 3.80 in the model estimated for sample 1 and 3.78 in the counterfactual model. The growth rate of investment is also affected, with an average growth rate of 6.93 in the model estimated for the first sample and 6.51 in the counterfactual model. There is no effect on consumption whose growth rate is 2.93. The growth rate of borrowing is 1.80 in the counterfactual model. Two main reasons explain this result. First, equation (24) shows that a 


\begin{tabular}{lc|cc}
\hline & Baseline & \multicolumn{2}{|c}{ Counterfactuals } \\
\hline Sample 1: 1965-1983 & & $\begin{array}{c}\text { Financial parameters } \\
\text { of sample 2 }\end{array}$ & $\begin{array}{c}\text { Structural and financial } \\
\text { parameters of sample 2 }\end{array}$ \\
GDP & 3.80 & 3.78 & 2.06 \\
Investment & 6.93 & 6.51 & 3.41 \\
Consumption & 2.93 & 2.93 & 1.71 \\
Borrowing & 1.07 & 1.80 & 0.52 \\
\hline & & Financial parameters & Structural and financial \\
Sample 2: 1984-2007 & & of sample 1 & parameters of sample 1 \\
GDP & 1.12 & 1.30 & 0.05 \\
Investment & -3.17 & -2.24 & -6.87 \\
Consumption & 1.27 & 1.03 & 0.38 \\
Borrowing & -5.34 & -7.77 & -9.10 \\
\hline
\end{tabular}

Table 7: Average 4-quarter growth rates after trough

higher steady state leverage ratio causes a smaller impact of the value of assets and net worth on the dynamics of borrowing. Capital and net worth are state variables, which slowly revert back to steady state. Therefore, when leverage is high, those state variables affect to a minor extent movements in borrowing, the growth rate of which becomes faster. Second, during the recovery phase borrowers have easier access to credit. The stronger financial accelerator in a highly leveraged economy measured by a higher elasticity of the external finance premium - also causes a faster recovery of credit. Overall, financial factors play a role in accounting for the speed of recovery, but it turns out to be small. We then simulate the outcomes of the pre-83Q4 shocks with the post-83Q4 parameters in place - both estimated structural and calibrated financial parameters. In this counterfactual model the average growth rate of GDP becomes 2.06, the growth rate of investment 3.41, the growth rate of consumption 1.71 and that of borrowing 0.52. Although the difference in growth rates between the estimated model and the counterfactual one is larger than that in the previous experiment, the difference in the mean growth rates across the two specifications is not statistically significant based on a one-sided t-test.

Table 7 also presents a similar exercise for sample 2. Data shows that the mean growth rates after trough of GDP is 1.12, of investment is -3.17 , of consumption is 1.27 and of borrowing is -5.34 . The speed of recovery of GDP, investment, consumption and borrowing is indeed much slower since the 1990s. The first counterfactual simulation consists in imposing the financial parameters of sample 1. This experiment shows that an economy with lower leverage, spread and business failure rate recovers faster: the average growth rate after trough of GDP is equal to 1.30 and of investment is equal to -2.24 . Hence financial factors affect the speed of recovery, but the difference in the mean growth rates is not statistically significant. The use of sample 1-parameters leads to an even slower recovery. ${ }^{13}$ This result is mainly explained by the different monetary policy parameters as shown in Appendix E.2.

\footnotetext{
${ }^{13}$ The difference in the mean growth rates of GDP and investment between the baseline specification and the counterfactual is statistically significant at $10 \%$ significance level.
} 


\begin{tabular}{lcccccccc}
\hline & & \multicolumn{5}{c}{ Structural shocks } \\
\hline & Wealth & Risk & Gov. & Mon. & Invest. & TFP & Price \\
premium & spending & policy & specific & Wage \\
mark-up & mark-up \\
\hline Output growth & $7.15 ; 8.64$ & $0.22 ; 0.68$ & $9.30 ; 16.18$ & $11.26 ; 12.32$ & $10.29 ; 20.71$ & $54.59 ; 34.55$ & $4.67 ; 6.60$ & $2.53 ; 0.31$ \\
Investment growth & $34.22 ; 27.57$ & $1.17 ; 2.66$ & $0.09 ; 0.15$ & $1.50 ; 3.62$ & $53.77 ; 62.44$ & $7.05 ; 1.68$ & $0.96 ; 1.20$ & $1.23 ; 0.67$ \\
Inflation & $53.55 ; 17.67$ & $0.74 ; 0.18$ & $3.84 ; 0.63$ & $1.92 ; 0.65$ & $4.92 ; 1.48$ & $11.93 ; 1.74$ & $15.92 ; 68.60$ & $7.18 ; 9.05$ \\
Interest rate & $61.98 ; 52.43$ & $0.99 ; 2.20$ & $4.22 ; 5.10$ & $9.00 ; 5.95$ & $8.51 ; 20.10$ & $7.07 ; 4.40$ & $4.60 ; 2.77$ & $3.61 ; 7.04$ \\
\hline
\end{tabular}

Table 8: Variance decomposition. The first number refers to the model estimated over the 1965-1983 sample while the second to the model estimated over the 1984-2007 sample

There are several reasons that could explain the limited role of financial factors in explaining the slow recoveries in the estimated model. First, the financial accelerator mechanism is likely to exert an effect more on the depth of the simulated recession rather than its persistence. Second, the Great Moderation is characterized by lower monitoring costs, which in turn implies a weaker financial accelerator effect. Third, the BGG model does not distinguish among sources of external finance. So it is not possible to disentangle developments in bank loans versus corporate bonds, which show considerable heterogeneity. Finally, the value of leverage in sample 1 is 1.40 , while it is 1.77 in sample 2. Appendix $\mathrm{C}$ shows some important non-linearities in the deep financial parameters. The observed difference in the leverage might not be large enough to generate substantial different dynamics in the model. It should also be noted that the slow recovery could be due to labour market mismatch (Şahin et al., 2014).

Given that the role of structural parameters is limited in affecting the speed of recovery, we now turn to the analysis of the variance decomposition to assess the importance of exogenous sources of fluctuations. Table 8 shows the TFP shock is the main driver of output growth in both samples. Monetary policy shocks play a non-negligible role in affecting GDP fluctuations, accounting for about $12 \%$ of its variation in both samples. As far as investment is concerned, there are some differences between the two samples. In the first sample the investment-specific technology shock accounts for about half of the fluctuations in investment growth, and the wealth shock explains $34 \%$ of its fluctuations, while in the second sample the investment-specific technology shock plays an even more important role. Overall, for both samples, the wealth and the investment-specific technology shocks account for about $90 \%$ of investment fluctuations. Wealth shocks play a role also in explaining inflation and the nominal interest rate, while mark-up shocks mainly affect movements in inflation.

\subsection{Impulse response function analysis}

This section discusses the impulse responses to the TFP, wealth and investment-specific technology shocks, which are the most important drivers of the US business cycle, as shown in Table 8. We conduct three different exercises. First, we show response functions of the models estimated over the two samples. Then, in order to disentangle the role of financial parameters, we estimate the model over the entire sample and we show IRFs for a model with sample 1 financial parameters versus one with sample 2 financial parameters. Finally, we investigate whether there exists a relationship 
between the speed of recovery from recessions and the magnitude of corporate leverage by changing a financial parameter at a time and reporting the impulse responses.

Figure 11 reports impulse responses of the two models: the one estimated over sample 1, 19651983; and the model estimated over sample 2, 1984-2007. The size of the shock is normalised to one standard deviation in all the charts.

The first row of Figure 11 shows the simulated recession driven by a TFP shock. This shock has a direct impact on output by making input less productive. The fall in the marginal productivity of capital leads to a fall in the return on capital expenditures, $R_{t}^{k}$. This in turn causes a decline in the value of the firm and hence in net worth, as evident from equations (21) and (22). The fall in net worth leads to a decrease in assets and hence generates a further retrenchment in capital and investment. The TFP shock causes a rise in the leverage which leads to an initial increase in the external financing costs, leading to a fall in borrowing. There are some crucial parameters that affect the depth of the recession and that are different from the two samples. The degree of price stickiness is higher during the Great Moderation, with retailers reoptimising prices almost every 2 and a half years compared to 2 quarters in the first sample. The interest rate smoothing is higher in sample 2 as well as the elasticity of capital utilisation. Since retailers change prices more often in sample 1, this causes a rise in inflation which is more pronounced. In addition, it is more costly to change the utilisation rate of capital in sample 2 - the elasticity is equal to 0.79 , while it is equal to 0.69 in sample 1 . Hence, a lower utilization rate further depresses aggregate production. In terms of growth rates after the trough, the 4-quarter growth rate is equal to 0.07 in sample 1 , higher than the corresponding growth rate in sample 2, equal to 0.03 . Hence the second sample features a slower recovery.

The immediate effect of a contractionary wealth shock is to decrease net worth, as evident from equation (21). The reduction in internal financing makes entrepreneurs more depending on external financing, hence debt increases. As a result, there is a higher probability of default and the threshold value of the idiosyncratic shock rises. Lenders hence require a higher premium. This causes a reduction in investment, and output due to the higher borrowing costs. The downward shift in aggregate demand leads to a fall in inflation. In both sample this shock is highly persistent, with an autoregressive coefficient of 0.98 in the first period and of 0.99 in the Great Moderation. This explains why the fall in net worth is even more long lasting in the second sample. The four-quarter growth rate after the trough of output is equal in the two samples. Hence, the response of output to a wealth shock does not feature a slower recovery during the Great Moderation.

The last row of Figure 11 shows the effects of an investment-specific technology shock. A contractionary investment-specific technology shock implies a rise in the price of capital, $Q_{t}$. But a change in the price of capital has two effects: (i) investment falls; and (ii) net worth of firms increases due to the higher return on capital. The latter effect causes a fall in the spread. This causes a less pronounced decline in investment. The presence of financial frictions, therefore, attenuates the fall in investment and output (see also Christensen and Dib, 2008). This shock does not replicate the positive co-movement between output and investment, at least on impact, as also noted by 
Villa (2016). The higher steady state leverage and the lower value of monitoring costs in sample 2, equation (22), explains the more pronounced increase in net worth, which leads to a stronger fall in the spread and a weaker fall in investment. The lower degree of price stickiness in sample 1 causes a fall in inflation which is more pronounced in this sample. The nominal interest rate increases by more in the first sample and this causes a more severe retrenchment in capital and investment. The four-quarter growth rate after the trough of output is 0.24 in the first sample and 0.27 in the second sample. Hence, the speed of recovery is slightly higher in the first sample.

Figure 11 makes it difficult to disentangle the role of financial versus structural parameters in affecting the speed of recovery. Hence, we estimate the model over the whole period, 1965Q1-2007Q4, calibrating the financial parameters to the values reported in Tables 2 and $3 .{ }^{14}$ We then show in Figure 12 impulse responses for a model with sample 1 financial parameters versus one with sample 2 financial parameters, while all the other parameters are the same between the two specifications. This exercise helps to isolate, from a graphical point of view, the role of financial conditions of the corporate sector in affecting the speed of recovery. Several results emerge. First, although the different financial conditions affect the responses of net worth and the spread, the overall impact on output and investment is small. As far as the TFP shock is concerned, the impulse responses of output and investment almost coincide under the two scenarios. Second, under sample 1 financial parameters there is a greater impact of a lower steady state leverage on the dynamics of debt, as explained in Section 3. This is particularly evident for the wealth shock. Third, an economy with a higher leverage and spread features a more severe recession in response to the investment-specific technology shock, but the speed of recovery is not affected. This figure confirms that the financial conditions of the corporate sector marginally affect the speed of recovery.

A natural question then arises: is there any parameterization of financial conditions that has a considerable impact on the model dynamics? Figure 13 shows impulse responses under four alternative scenarios: (i) sample 1 but with a period of changing prices of 6 quarters $\left(\sigma_{p}=0.835\right)$; (ii) a model where the volatility of the idiosyncratic shock, $\sigma$, is equal to 0.05 , while all the other parameters are those of scenario (i); (iii) a model where monitoring costs, $\mu$, are equal to 0.001, with all the other parameters of scenario (i); and (iv) a model where the survival rate, $\theta$, is equal to 0.925 , with all the other parameters of scenario (i). Hence in each model we change one financial parameter at a time. The latter three models imply a higher leverage equal to 5.83, 5.36, and 1.82 for $\sigma=0.05, \mu=0.001$ and $\theta=0.925$ respectively. While the first two models feature a low steady state spread, changing $\theta$ leads to an implausible high spread, greater than a thousand basis points py. We impose a higher degree of price stickiness than that of sample 1 because in the presence of stickier prices the change in inflation is moderate and so is the change in the nominal interest rate. This clearly affects the dynamics of capital and investment, allowing financial factors to play a larger role. This is a ceteris paribus exercise since $\sigma_{p}$ is the same in all the four scenarios.

Under this alternative parameterization, financial factors do affect the dynamic properties of the model. As far as the depth of the recession is concerned, lower monitoring costs and volatility of the

\footnotetext{
${ }^{14}$ Table 20 in Appendix shows the posterior distributions of parameters and shocks.
} 
idiosyncratic shock make the recession less severe in the case of the wealth shock due to the limited financial accelerator effect. In fact, with $\sigma$ and $\mu$ low, the threshold value of the idiosyncratic shock is around 0.90, which implies a low elasticity of the external finance premium. In the case of the investment shock, the contraction in investment is more pronounced because there is a much weaker fall in the spread. The model with a low $\theta$, instead, features a larger response of the spread due to the higher value of the elasticity of the external finance premium. A stronger financial accelerator effect causes a more severe contraction in output and investment in the case of the TFP and wealth shock, while a moderate fall in real variables in the case of the investment shock, which is characterized by the decline in the spread.

The role of financial conditions as an endogenous cause of slower recovery is limited in response to the TFP shock and the wealth shock. It is worth noting that those shocks feature a high persistence, with an AR (1) coefficient of 0.98 , as shown in Table 6. The lower exogenous persistence of the investment-specific technology shock - whose AR (1) coefficient is 0.55 - makes the financial conditions of the corporate sector relevant. In fact, the 4-quarter growth rate after trough is 0.25 in sample 1 , and it decreases to 0.14 when $\mu$ is equal to 0.01 and to 0.17 for $\sigma=0.05$. Hence the models featuring higher leverage experience a slower recovery, as observed in the data. The model is thus able to imply a relationship between the speed of recovery from recessions and the magnitude of corporate leverage in these cases.

We further investigate the role of endogenous versus exogenous factors affecting the speed of recovery. We conduct another counterfactual experiment where we impose that the TFP and the wealth shocks have the same persistence and standard deviation of the investment-specific technology shock - whose persistence is lower than that of the other two shocks. We then simulate the outcomes of the pre-83Q4 shocks (where TFP and wealth shocks are "modified") with the post-83Q4 financial parameters in place. The purposes of this exercise are mainly two: first, investigating the role of less persistent shocks and, second, disentangling the role of shocks versus financial factors in causing the slow recoveries. The effect of less persistent TFP and wealth shocks leads to a slower recovery in an economy featuring a higher leverage. In fact, the 4-quarter growth rate of GDP becomes equal to 2.71 , while it is equal to 3.80 in the baseline specification and it is equal to 3.78 in the model featuring only the financial parameters of sample 2 , as shown in Table 7 . The 4-quarter growth rate of investment becomes 6.26 and that of consumption 1.40. This experiment makes it clear that the exogenous processes are the main reason for the slow recoveries during the recent period, in line with the findings of Galí et al. (2012).

\section{Concluding remarks}

This paper analyses whether financial conditions of the corporate business sector can account for the slow recoveries since the mid-1980s.

Data on the US post-WWII economy show that the change in the speed of recovery of output since the mid-1980s is also mirrored by a corresponding change in the 4- and 8- quarter growth rate after 
trough of investment and bank borrowing by the corporate sector. However, the 4-quarter growth rate of corporate bonds is higher during the Great Moderation, revealing different developments of corporate indebtedness depending on the sources of external finance. The paper also documents that leverage and the business failure rate in the corporate business sector have increased since the mid-1980s, while the external finance premium has not risen that much.

In a DSGE model with a financial accelerator à la Bernanke et al. (1999) we show that an economy featuring a lower leverage recovers faster, but the difference in the growth rates between a model economy with lower and higher leverage is not statistically significant. Financial conditions in the business sector affect only marginally the difference in the growth rates of output, investment and consumption, before and after the mid-1980s. This result is confirmed by impulse response function analysis. Several reasons can explain this result. First, the financial accelerator mechanism is likely to exert a stronger impact on the depth of the simulated recession rather than on its persistence. Second, the process of financial deregulation during the Great Moderation, captured in the model by the reduction in monitoring costs, implies a weaker financial accelerator effect. Third, the DSGE model does not distinguish between alternative sources of external finance, which display different growth rates after trough since the mid-1980s. Finally, non-linearities can have considerable impact on the model dynamics. The difference in the values of leverage across the two samples might be not large enough to generate a significant difference in the speed of recovery. Galí et al. (2012) find that the risk premium and the investment shocks, as well as adverse wage markup and monetary policy shocks, are the main factors behind the slow recoveries. A deeper analysis on the structural interpretation of these shocks could help understand the slower speed of recoveries in the US economy since the mid-1980s.

\section{References}

Allen, F., Chui, M. K., and Maddaloni, A. (2004). Financial systems in Europe, the USA, and Asia. Oxford Review of Economic Policy, 20(4):490-508.

Altman, E. and Kuehne, B. (2012). Defaults and returns in the high-yield bond and distressed debt market: The year 2011 in review and outlook. NYU Salomon Center.

Bernanke, B., Gertler, M., and Gilchrist, S. (1999). The financial accelerator in a quantitative business cycle model. Handbook of Macroeconomics, 1:1341-1393.

Bernanke, B. S., Gertler, M., and Gilchrist, S. (1996). The flight to quality and the financial accelerator. Review of Economics and Statistics, 78(1):1-15.

Brunnermeier, M., Eisenbach, T., and Sannikov, Y. (2012). Macroeconomics with financial frictions: A survey. NBER Working Papers, 18102.

Carrillo, J. and Poilly, C. (2013). How do financial frictions affect the spending multiplier during a liquidity trap? Review of Economic Dynamics, 16(2):296-311.

Christensen, I. and Dib, A. (2008). The financial accelerator in an estimated New Keynesian model. Review of Economic Dynamics, 11,1:155-178. 
Christiano, L., Motto, R., and Rostagno, M. (2014). Risk Shocks. American Economic Review, 104(1):27-521.

Christiano, L., Rostagno, M., and Motto, R. (2010). Financial factors in economic fluctuations. ECB Working Paper Series, 1192.

Coenen, G., Levin, A., and Christoffel, K. (2007). Identifying the influences of nominal and real rigidities in aggregate price-setting behavior. Journal of Monetary Economics, 54(8):2439-2466.

Covas, F. and Den Haan, W. (2011). The cyclical behavior of debt and equity finance. American Economic Review, 101(2):877-899.

De Graeve, F. (2008). The external finance premium and the macroeconomy: US post-WWII evidence. Journal of Economic Dynamics and Control, 32(11):3415-3440.

Del Negro, M. and Schorfheide, F. (2013). DSGE model-based forecasting. Handbook of Economic Forecasting, 2:57-140.

Fernández, A. and Gulan, A. (2015). Interest rates and business cycles in emerging economies: The role of financial frictions. American Economic Journal: Macroeconomics, 7(3):153-88.

Fuentes-Albero, C. (2014). Financial frictions, financial shocks, and aggregate volatility. Finance and Economics Discussion Series, Federal Reserve Board, 2014-84.

Galí, J., Smets, F., and Wouters, R. (2011). Unemployment in an estimated New Keynesian model. NBER Macroeconomics Annual, 26(1):329-360.

Galí, J., Smets, F., and Wouters, R. (2012). Slow recoveries: A structural interpretation. Journal of Money, Credit and Banking, 44(2):9-30.

Geanakoplos, J. (2010). The leverage cycle. NBER Macroeconomic Annual, 24:1-65.

Gelain, P. (2010). The external finance premium in the euro area: A useful indicator for monetary policy? ECB Working Paper, 1171.

Gertler, M. and Gilchrist, S. (1993). The role of credit market imperfections in the monetary transmission mechanism: arguments and evidence. The Scandinavian Journal of Economics, 95(1):43-64.

Gertler, M. and Karadi, P. (2011). A model of unconventional monetary policy. Journal of Monetary Economics, 58(1):17-34.

Gilchrist, S. and Zakrajšek, E. (2012). Credit spreads and business cycle fluctuations. American Economic Review, 102(4):1692-1720.

Jermann, U. and Quadrini, V. (2012). Macroeconomic effects of financial shocks. American Economic Review, 102(1):238-271.

Jordà, Ò., Schularick, M., and Taylor, A. M. (2013). When credit bites back. Journal of Money, Credit and Banking, 45(s2):3-28.

Justiniano, A., Primiceri, G. E., and Tambalotti, A. (2013). Household leveraging and deleveraging. Review of Economic Dynamics, 18(1):3-20.

Kamber, G. and Thoenissen, C. (2012). The financial accelerator and monetary policy rules. Economics Letters, 115:309-313.

Levin, A., Natalucci, F., and Zakrajsek, E. (2004). The magnitude and cyclical behavior of financial 
market frictions. FEDS Working Paper, 2004-70.

Lown, C. S. and Morgan, D. P. (2006). The credit cycle and the business cycle: new findings using the loan officer opinion survey. Journal of Money, credit, and Banking, 38(6):1575-1597.

Meier, A. and Muller, G. (2006). Fleshing out the monetary transmission mechanism: Output composition and the role of financial frictions. Journal of Money, Credit, Banking, 38:1999-2133.

Mertens, K. and Ravn, M. O. (2011). Leverage and the financial accelerator in a liquidity trap. The American Economic Review, 101(3):413-416.

Mumtaz, H. and Zanetti, F. (2016). The effect of labor and financial frictions on aggregate fluctuations. Macroeconomic Dynamics, 20(01):313-341.

Ng, S. and Wright, J. H. (2013). Facts and challenges from the great recession for forecasting and macroeconomic modeling. Journal of Economic Literature, 51(4):1120-1154.

Şahin, A., Song, J., Topa, G., and Violante, G. L. (2014). Mismatch unemployment. American economic review, 104(11):3529-64.

Smets, F. and Wouters, R. (2007). Shocks and frictions in US business cycles: A Bayesian DSGE approach. American Economic Review, 97(3):586-606.

Townsend, R. (1979). Optimal contracts and competitive markets with costly state verification. Journal of Economic theory, 21(2):265-93.

Villa, S. (2016). Financial frictions in the Euro Area and the United States: a Bayesian assessment. Macroeconomic dynamics. Forthcoming.

von Heideken, V. (2009). How Important are Financial Frictions in the United States and the Euro Area? Scandinavian Journal of Economics, 111(3):567-596. 


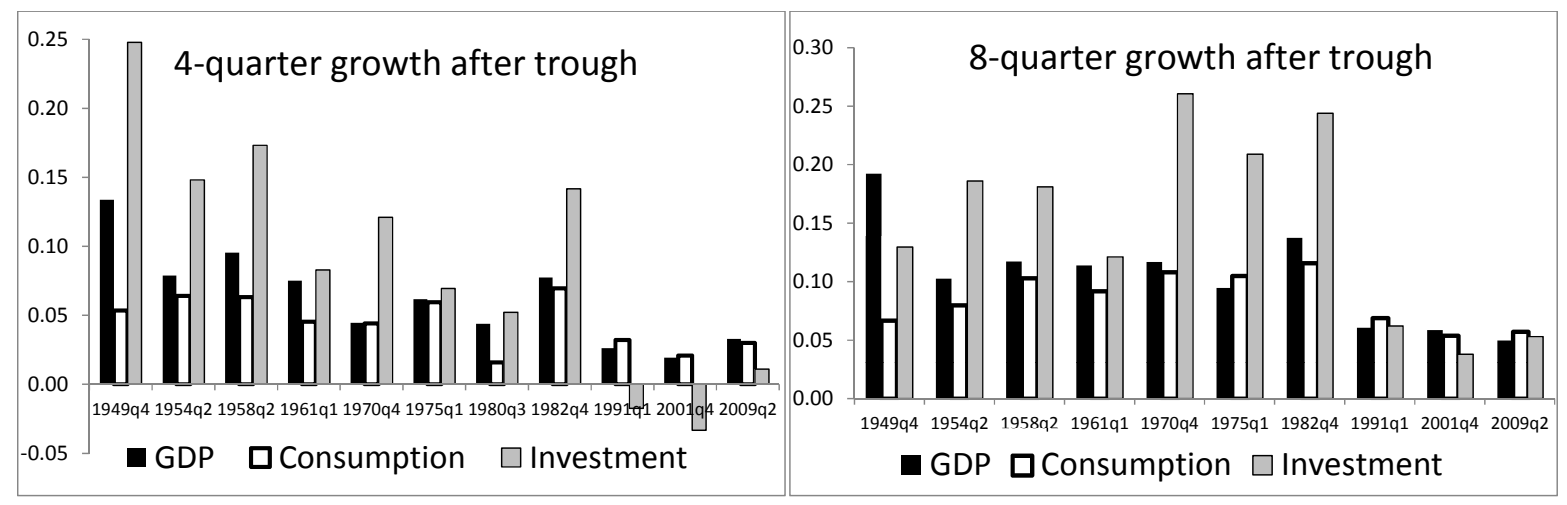

Figure 1: Speed of recovery of GDP, consumption and investment
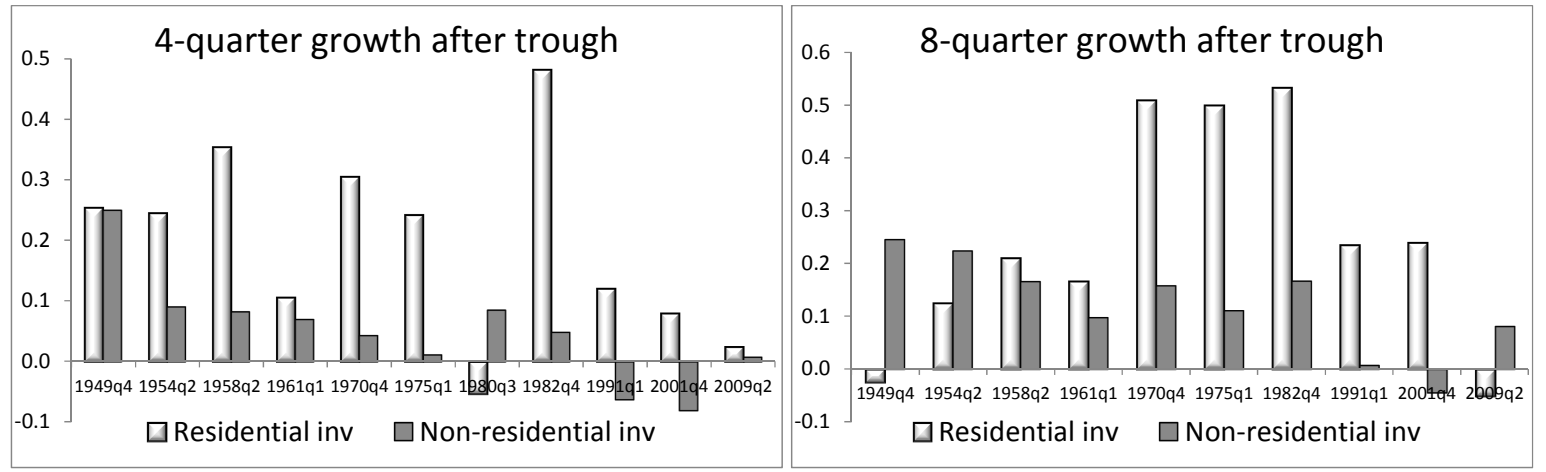

Figure 2: Speed of recovery of residential and non-residential investment

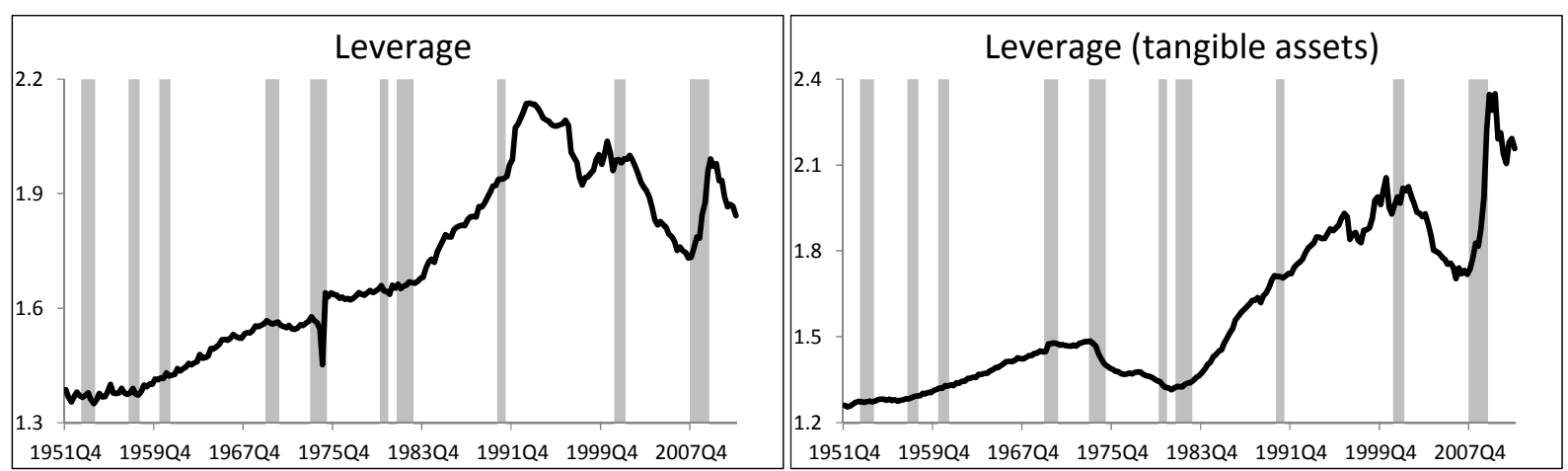

Figure 3: The left chart shows data on the leverage (total assets/net worth) of the non-financial corporate business sector. In the right chart leverage is computed as the ratio between tangible assets and net worth, defined as tangible assets minus credit market liabilities. Source: Flow of Funds Accounts, Federal Reserve Board, Table B.102 


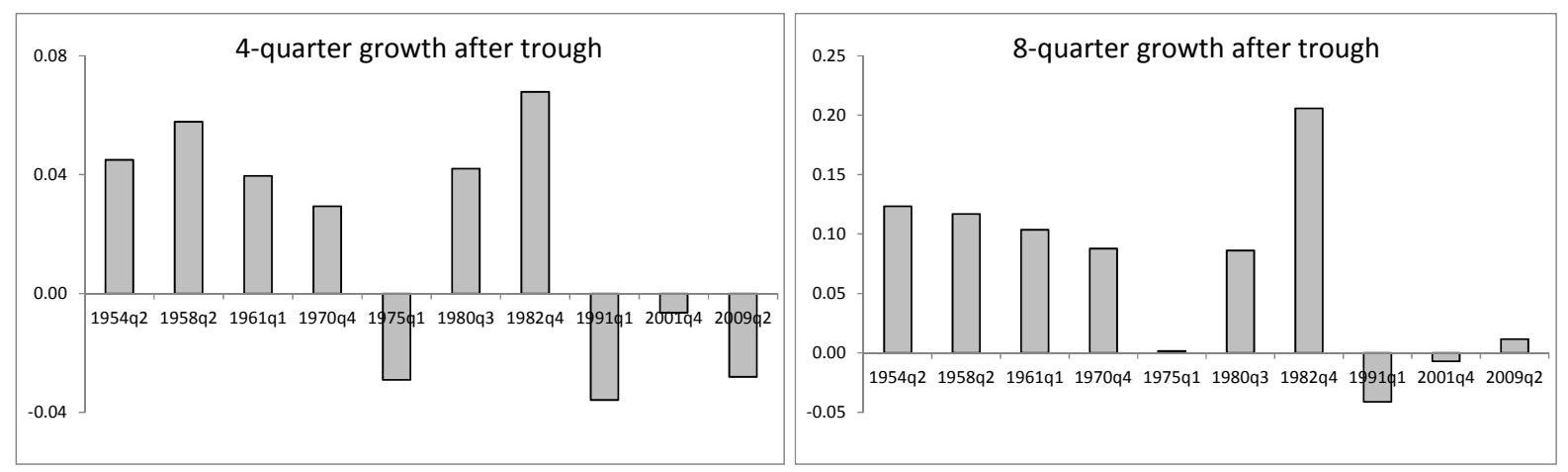

Figure 4: Speed of recovery of credit market instruments outstanding by the non-financial corporate business sector

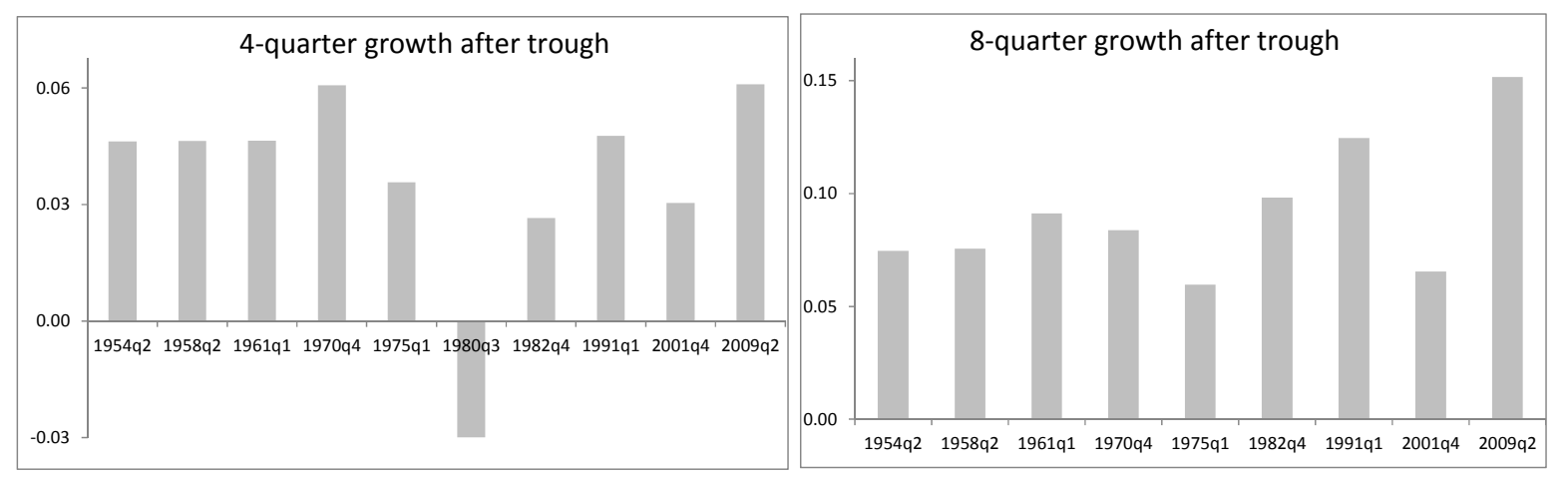

Figure 5: Speed of recovery of corporate bonds by the non-financial corporate business sector

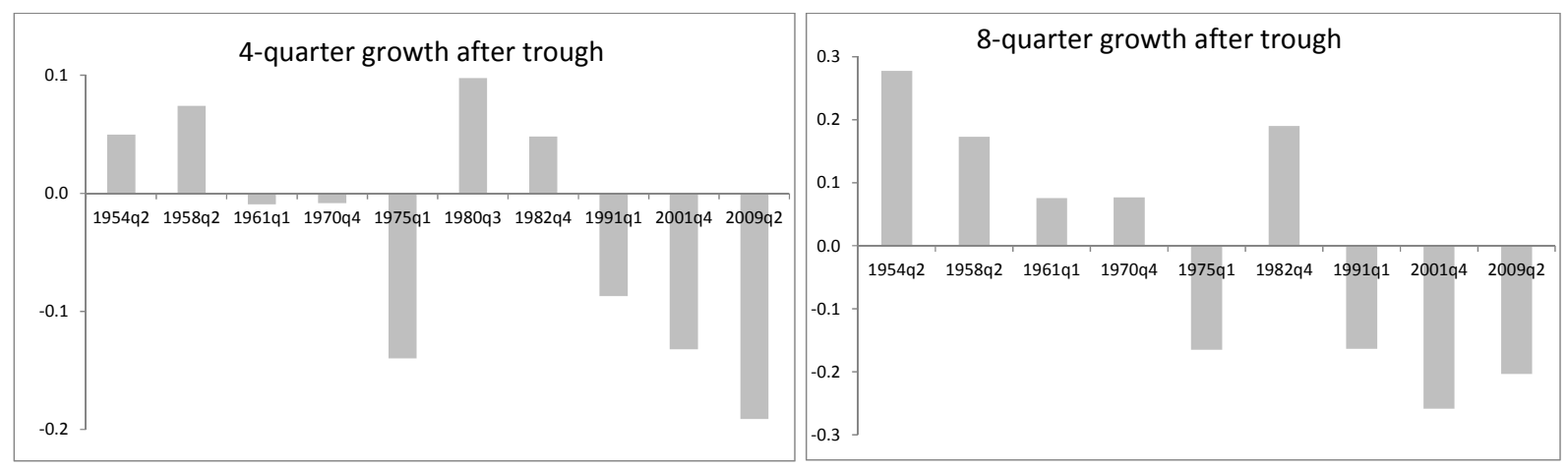

Figure 6: Speed of recovery of depository institution loans to the non-financial corporate business sector 


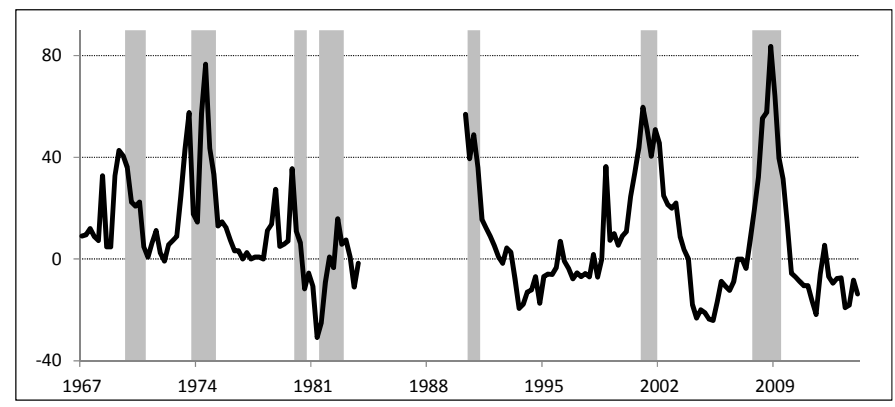

Figure 7: Net percentage change in lending standards for C\&I loans to large and middle-market firms. Between 1984 and 1990 the Senior Loan Officer Opinion Survey has not been conducted. Source: Lown and Morgan (2006)

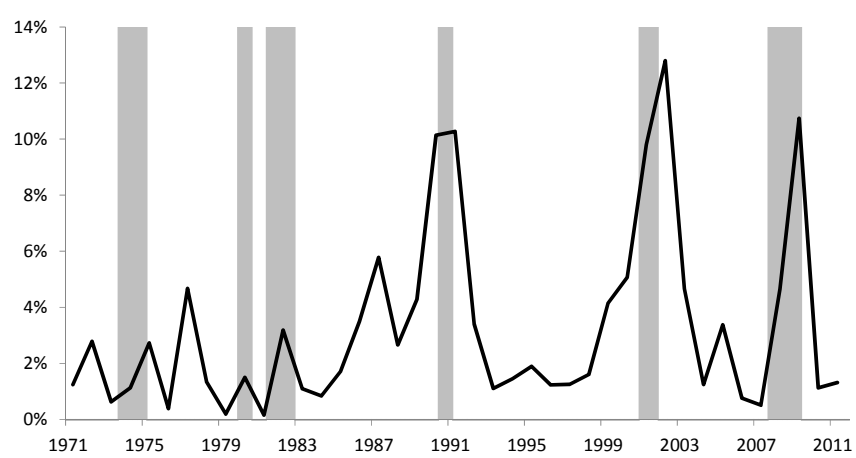

Figure 8: (High-yield bond) Default rates. Source: Altman and Kuehne (2012)

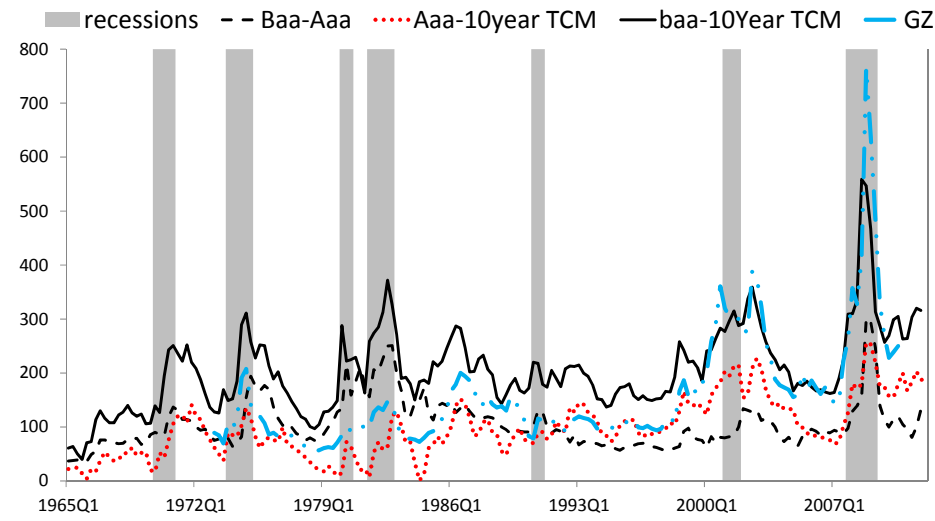

Figure 9: Series of the spread in basis points. Sources: ALFRED database St. Louis Fed and Gilchrist and Zakrajšek (2012) (GZ) 


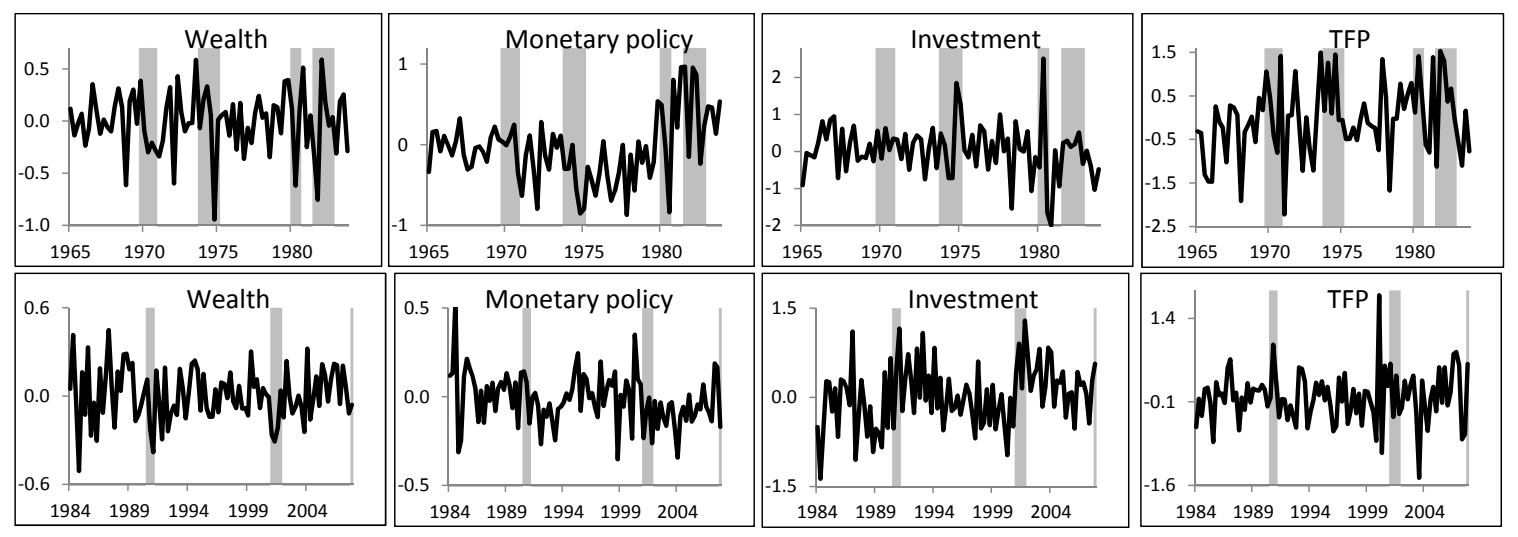

Figure 10: Estimated smoothed shocks which are the main important drivers of US business cycles. Shaded bars represent NBER recessions
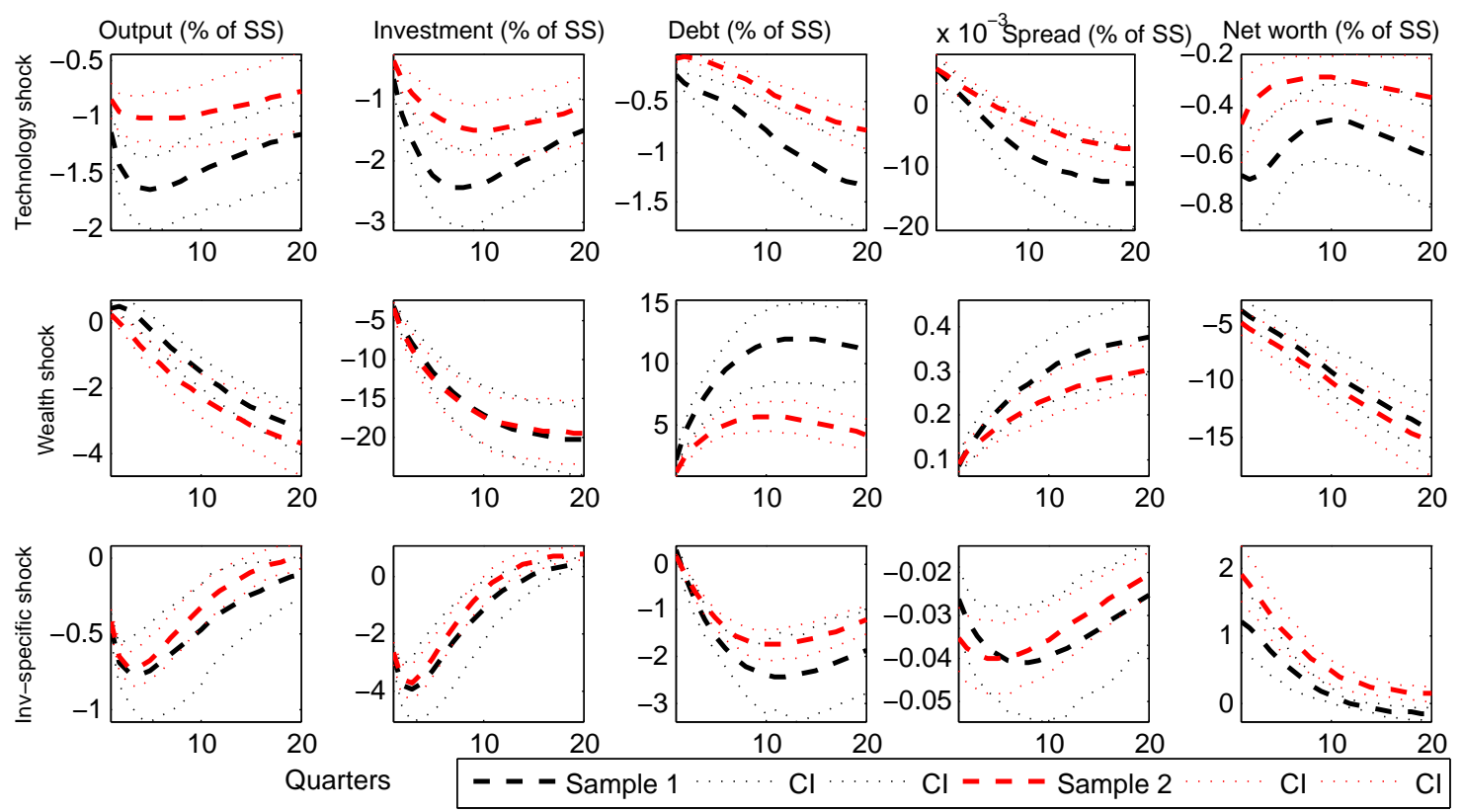

Figure 11: Impulse responses to TFP, wealth and investment-specific technology shocks. Dashed lines represent mean responses and dotted lines represent the $95 \%$ confidence intervals. The size of the shocks is normalized to one standard deviation. Sample 1 refers to the period 1965-1983, while sample 2 to the period 1984-2007 

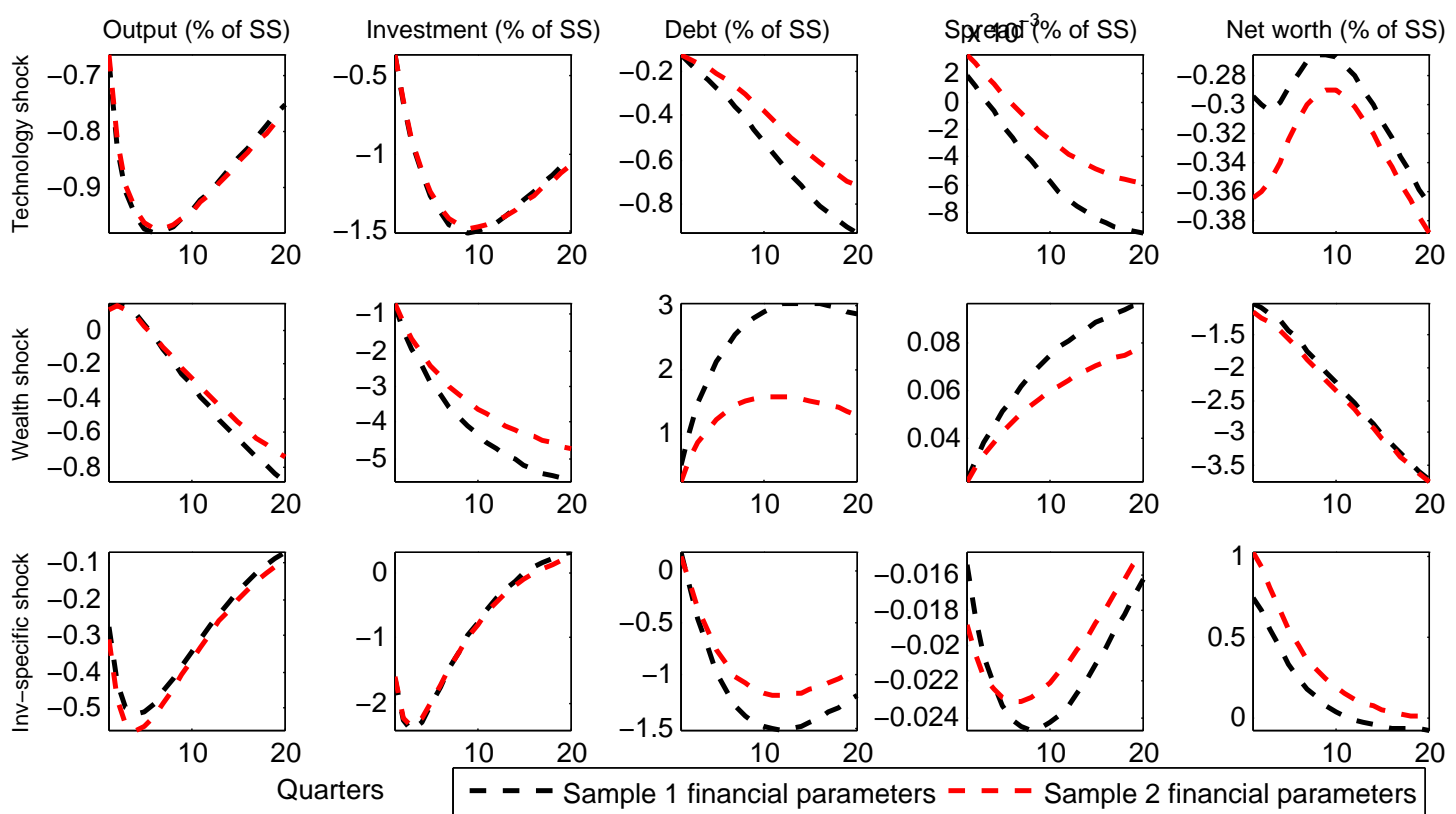

Figure 12: Impulse responses to TFP, wealth and investment-specific technology shocks in the model estimated over the entire sample (1965-2007). Sample 1 refers to the period 1965-1983, while sample 2 to the period $1984-2007$
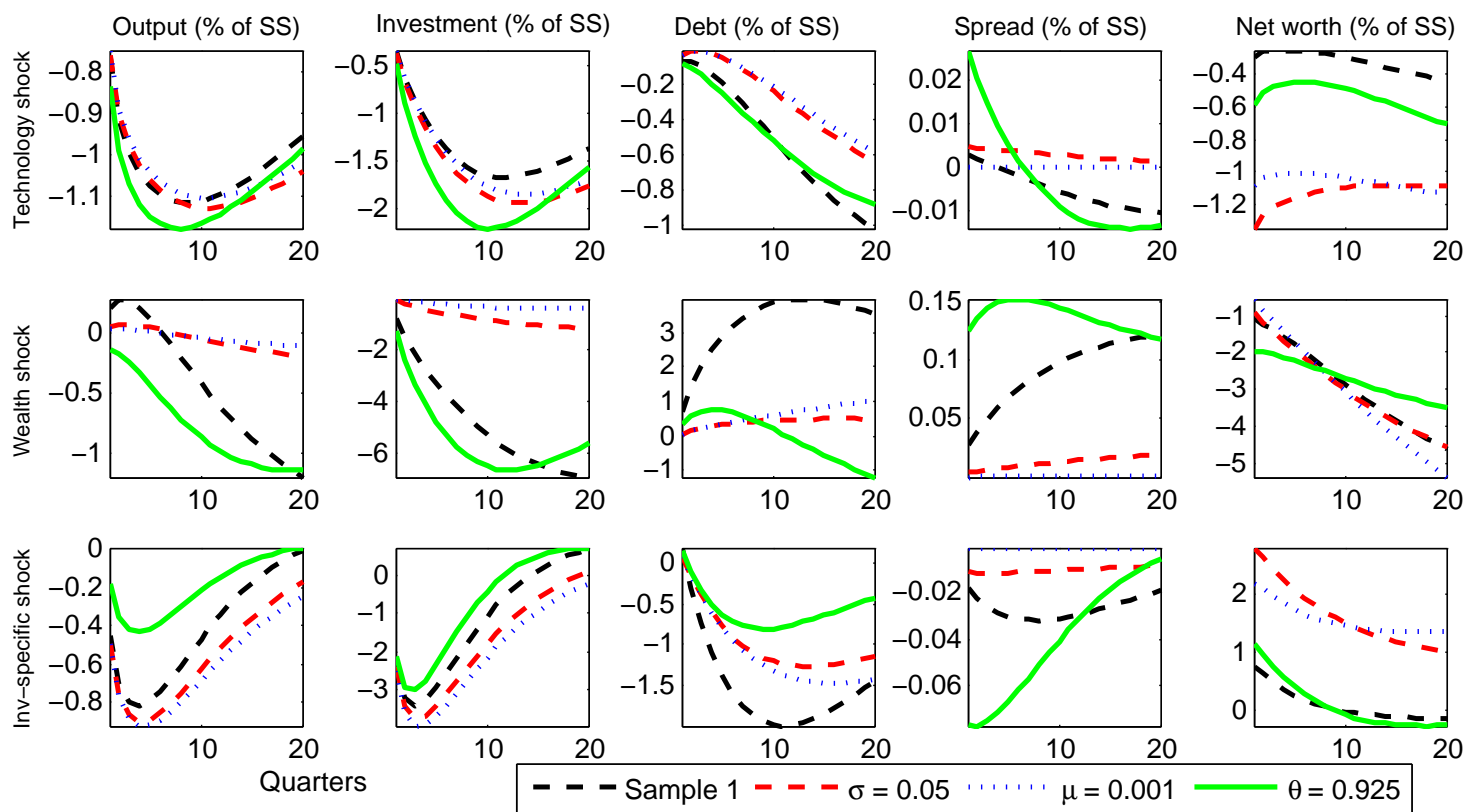

Figure 13: Impulse responses to TFP, wealth and investment-specific technology shocks. Sample 1 refers to the period 1965-1983 


\section{Appendix}

\section{A Data Appendix}

Data on real output, real personal consumption expenditure and real fixed private investment are taken from NIPA Table 1.1.5 of the Bureau of Economic Analysis.

Data on the corporate financial sector are taken from the Flow of Funds of the Federal Reserve Board, Table B.102. Non-financial assets consist of real estate (at market value), equipment and software, and inventories (at replacement cost). Credit market instruments consist of commercial paper, municipal securities, corporate bonds, depository institutions loans, other loans and advances, and mortgages. Total liabilities consist of credit market instruments, corporate equities, trade payables, taxes payables and miscellaneous liabilities, of the non-financial corporate business sector. The dataset start in 1951Q4, hence the 1949 recession is not included. Financial data are deflated using the GDP deflator.

The analysis of growth rates after trough of alternative measures of indebtedness of the nonfinancial corporate sector does not assume any causal relationship with GDP. A detailed discussion on the "finance-growth nexus" is well beyond the scope of the paper. Notwithstanding this, crosscorrelation analysis could provide a clearer picture on the lag/lead relationships between corporate indebtedness and GDP. Table 9 shows the cross-correlation between HP component of corporate debt and HP component of GDP. ${ }^{15}$ All the measures of corporate debt are pro-cyclical, with the exception of corporate bonds, which is almost a-cyclical. Total liabilities, credit market liabilities and depository institution loans lag the cycle by approximately one year, while corporate bonds lag the cycle by more than two years. The paper investigates the different mechanisms through which corporate indebtedness might affect GDP, but it is important to take into account that corporate indebtedness is endogenously determined. A DSGE model is an appropriate instrument to investigate these issues.

This appendix also presents some data on the liability side of the household sector and of all commercial banks in the US economy.

Data on household indebtedness (Table B.100, Flow of Funds) reveal that households leverage, i.e. the ratio between the value of real estate and the owners' equity in real estate, has dramatically increased only in the latest financial crisis. As shown in Figure 14, it is not possible to detect a statistically significant difference in growth rates pre- and post-1990 for indebtedness of the households sector. This result is confirmed in Table 10, which reports also the average 4-quarter and 8-quarter growth rates of home mortgage liabilities. We cannot reject the null hypothesis of equal mean of both the 4-quarter and 8-quarter growth rates pre- and post- $1990 .^{16}$

Table 10 also shows the 4-quarter and 8-quarter growth rates of indebtedness of all commercial banks (Table H.8, Federal Reserve Board). Data are available from 1973Q1. Hence, this exercise considers only three recessions before the 1990s. Total liabilities are given by the sum of deposits,

\footnotetext{
${ }^{15}$ Results are qualitatively similar when applying a Band-pass filter.

${ }^{16}$ For the role of households indebtedness in recent times see Justiniano et al. (2013), among others.
} 


\begin{tabular}{|c|c|c|c|c|}
\hline Variable & Tot. liabilities & Credit mark. liabilities & Corporate bonds & Depos. institut. loans \\
\hline $\mathrm{t}=-12$ & 0.03 & -0.11 & 0.24 & -0.27 \\
\hline $\mathrm{t}=-11$ & 0.12 & -0.01 & 0.25 & -0.17 \\
\hline $\mathrm{t}=-10$ & 0.20 & 0.09 & 0.26 & -0.07 \\
\hline $\mathrm{t}=-9$ & 0.29 & 0.18 & 0.25 & 0.03 \\
\hline $\mathrm{t}=-8$ & 0.36 & 0.28 & 0.25 & 0.13 \\
\hline $\mathrm{t}=-7$ & 0.42 & 0.40 & 0.24 & 0.29 \\
\hline $\mathrm{t}=-6$ & 0.46 & 0.50 & 0.21 & 0.42 \\
\hline$t=-5$ & 0.47 & 0.55 & 0.14 & 0.52 \\
\hline $\mathrm{t}=-4$ & 0.46 & 0.57 & 0.08 & 0.58 \\
\hline $\mathrm{t}=-3$ & 0.44 & 0.55 & 0.01 & 0.59 \\
\hline $\mathrm{t}=-2$ & 0.39 & 0.51 & -0.04 & 0.55 \\
\hline $\mathrm{t}=-1$ & 0.33 & 0.45 & -0.06 & 0.49 \\
\hline$t=0$ & 0.24 & 0.36 & -0.04 & 0.40 \\
\hline $\mathrm{t}=1$ & 0.13 & 0.26 & 0.01 & 0.28 \\
\hline $\mathrm{t}=2$ & 0.02 & 0.14 & 0.05 & 0.14 \\
\hline$t=3$ & -0.10 & 0.05 & 0.07 & 0.03 \\
\hline $\mathrm{t}=4$ & -0.21 & -0.04 & 0.07 & -0.05 \\
\hline $\mathrm{t}=5$ & -0.32 & -0.10 & 0.07 & -0.12 \\
\hline $\mathrm{t}=6$ & -0.39 & -0.16 & 0.05 & -0.16 \\
\hline $\mathrm{t}=7$ & -0.43 & -0.20 & 0.02 & -0.21 \\
\hline $\mathrm{t}=8$ & -0.42 & -0.23 & 0.00 & -0.26 \\
\hline $\mathrm{t}=9$ & -0.39 & -0.25 & -0.03 & -0.28 \\
\hline $\mathrm{t}=10$ & -0.33 & -0.27 & -0.07 & -0.25 \\
\hline $\mathrm{t}=11$ & -0.26 & -0.27 & -0.11 & -0.22 \\
\hline $\mathrm{t}=12$ & -0.16 & -0.26 & -0.15 & -0.17 \\
\hline
\end{tabular}

Table 9: Cross-correlation with $G D P_{t+k}$

borrowings, trading liabilities and other liabilities; deposits account for $77 \%$ of total liabilities over the sample period. Similarly to the household sector, we cannot reject the null hypothesis of equal mean of both the 4-quarter and 8-quarter growth rates pre- and post- 1990. The last row of Table 10 shows the growth rates of borrowing of all commercial banks, which is the sum of borrowings from banks in the US and from others. The difference in both the 4-quarter and 8-quarter growth rates of borrowing is not statistically significant. As evident from Figure 15, growth rates are different only in the latest crisis.

\section{B The Model}

\section{B.1 The financial contract}

As explained by Bernanke et al. (1999), the optimal financial contract specifies a cutoff value for the idiosyncratic shock, $\bar{\omega}$, such that if $\omega \geq \bar{\omega}$ the entrepreneur is able to repay the loan. Alternatively, if $\omega \leq \bar{\omega}$ the borrower gets nothing, the lender pays the auditing costs and his net receipts are $(1-\mu) \omega_{t+1} R_{t+1}^{k} Q_{t} K_{t+1}$. Let $\bar{\omega}$ be the threshold value of the shock $\omega$ such that if $\omega \geq \bar{\omega}$ the 

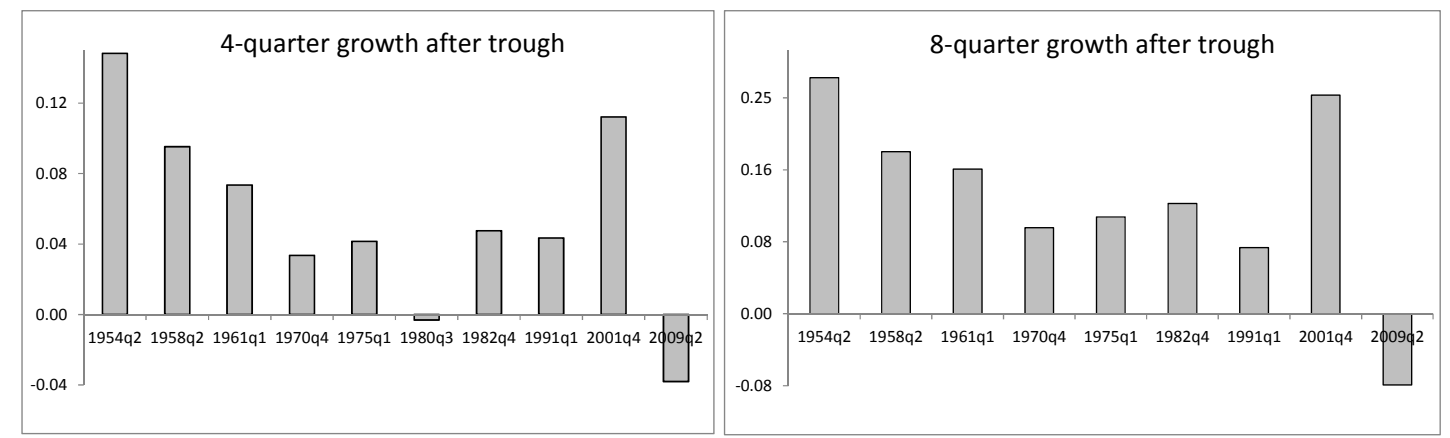

Figure 14: Speed of recovery of real debt (home mortgages) by households

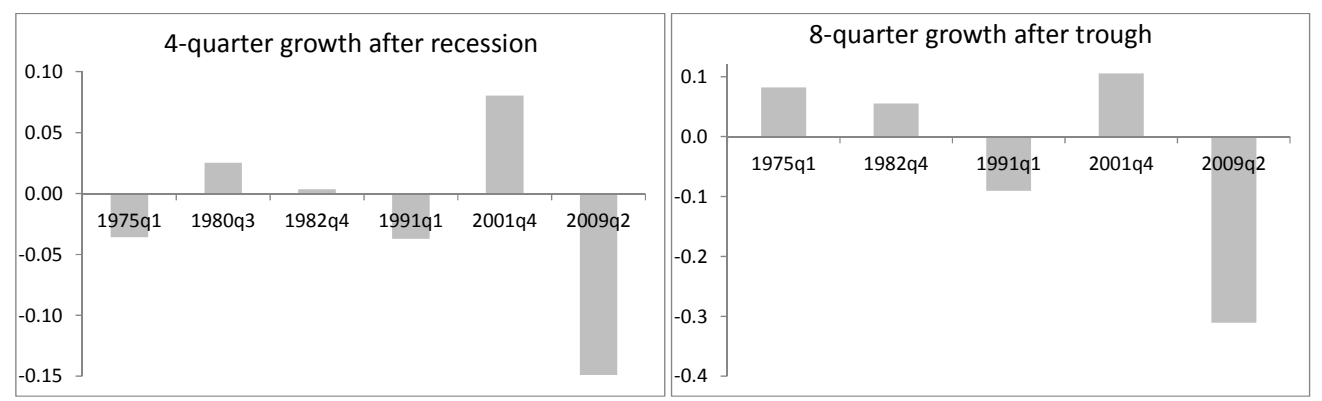

Figure 15: Speed of recovery of real borrowings by all commercial banks

\begin{tabular}{|c|c|c|c|c|c|c|}
\hline & \multicolumn{4}{|c|}{ 4-quarter growth } & \multicolumn{2}{|c|}{ 8-quarter growth } \\
\hline & Pre-90 & Post-90 & Change & Pre-90 & Post-90 & Change \\
\hline Household sector & & & & & & \\
\hline Liabilities (home mortgages) & 6.24 & 3.92 & 2.32 & 15.88 & 8.12 & 7.76 \\
\hline All commercial banks & & & & & & \\
\hline Total liabilities & 1.88 & 0.52 & 1.35 & 4.68 & 2.01 & 2.67 \\
\hline Borrowings & -0.24 & -3.52 & 3.28 & 6.85 & -9.87 & 16.72 \\
\hline
\end{tabular}

* denotes rejection of the null hypothesis of equal means at $10 \%$ significance level of a one-sided t-test.

The 8-quarter growth rates do not take into account the recession in 1980.

Table 10: Speed of recoveries (in percent) of different measure of household and financial-sector indebtedness in the two subsamples

entrepreneur is able to repay the loan at the contractual rate $R_{t}^{l}$. The threshold value, $\bar{\omega}$, is defined by:

$$
\bar{\omega}_{t+1} R_{t+1}^{k} Q_{t} K_{t+1}=R_{t}^{l} B_{t+1}
$$

In this case the entrepreneur repays the lender the amount $R_{t}^{l} B_{t+1}$ and keeps the difference equal to $\omega_{t+1} R_{t+1}^{k} Q_{t} K_{t+1}-R_{t}^{l} B_{t+1}$. If $\omega<\bar{\omega}$, the entrepreneur declares default, the lender pays the auditing costs and his net receipts are $(1-\mu) \omega_{t+1} R_{t+1}^{k} Q_{t} K_{t+1}$. The entrepreneur receives nothing. The loan 
contract must satisfy the condition that the return on the loan to the entrepreneur must be equal to the opportunity cost of lending, in terms of the risk free rate. And the entrepreneur wants to maximize its expected return defined as:

$$
E\left\{\int_{\bar{\omega}_{t+1}}^{\infty} \omega d F(\omega) R_{t+1}^{k} Q_{t} K_{t+1}-\left[1-F\left(\bar{\omega}_{t+1}\right)\right] \bar{\omega}_{t+1} R_{t+1}^{k} Q_{t} K_{t+1}\right\}
$$

where the second term represents the cost of borrowing. The optimal contracting problem can thus be written as:

$$
\begin{array}{ll}
\max _{K, \bar{\omega}} & \left(1-\Gamma\left(\bar{\omega}_{t}\right)\right) R_{t}^{k} Q_{t-1} K_{t} \\
\text { s.t. } & {\left[\Gamma\left(\bar{\omega}_{t}\right)-\mu G\left(\bar{\omega}_{t}\right)\right] R_{t}^{k} Q_{t-1} K_{t}=R_{t}\left(Q_{t-1} K_{t}-N_{t}\right)}
\end{array}
$$

where the net share of profits going to the lender is $\Gamma(\bar{\omega})-\mu G(\bar{\omega})$, the gross share is $\Gamma(\bar{\omega})=$ $\int_{0}^{\bar{\omega}} \omega f(\omega) d \omega+\bar{\omega} \int_{\bar{\omega}}^{\infty} \omega f(\omega) d \omega, \Gamma^{\prime}(\bar{\omega})=1-F(\bar{\omega}), \Gamma^{\prime \prime}(\bar{\omega})=-f(\bar{\omega})$. The monitoring costs are defined as $\mu G(\bar{\omega})=\mu \int_{0}^{\bar{\omega}} \omega f(\omega) d \omega$ and $G^{\prime}(\bar{\omega})=\bar{\omega} f(\bar{\omega})$.

Define $s=\frac{R^{k}}{R}, k=\frac{Q K}{N}$ (the leverage ratio), and $\lambda$ the Lagrange multiplier. The first order conditions are:

$$
\begin{aligned}
\bar{\omega}: & \Gamma^{\prime}\left(\bar{\omega}_{t}\right)-\lambda_{t}\left[\Gamma^{\prime}\left(\bar{\omega}_{t}\right)-\mu G^{\prime}\left(\bar{\omega}_{t}\right)\right]=0 \\
k: & \left\{\left(1-\Gamma\left(\bar{\omega}_{t}\right)\right)+\lambda_{t}\left[\Gamma\left(\bar{\omega}_{t}\right)-\mu G\left(\bar{\omega}_{t}\right)\right]\right\} s_{t}-\lambda_{t}=0 \\
\lambda: & {\left[\Gamma\left(\bar{\omega}_{t}\right)-\mu G\left(\bar{\omega}_{t}\right)\right] s_{t} k_{t}-\left(k_{t}-1\right)=0 }
\end{aligned}
$$

Then

$$
\begin{aligned}
\lambda_{t} & =\frac{\Gamma^{\prime}\left(\bar{\omega}_{t}\right)}{\left[\Gamma^{\prime}\left(\bar{\omega}_{t}\right)-\mu G^{\prime}\left(\bar{\omega}_{t}\right)\right]} \\
s_{t} & =\frac{\lambda_{t}}{\lambda_{t}\left[\Gamma\left(\bar{\omega}_{t}\right)-\mu G\left(\bar{\omega}_{t}\right)\right]+\left(1-\Gamma\left(\bar{\omega}_{t}\right)\right)} \\
k_{t} & =\frac{1}{\left(1-\left[\Gamma\left(\bar{\omega}_{t}\right)-\mu G\left(\bar{\omega}_{t}\right)\right] s_{t}\right)}
\end{aligned}
$$

Therefore $s, k$ and $\lambda$ are function of $\bar{\omega}$. When $\mu=0$, then $\lambda=1$ and $s=1$; hence financial markets become frictionless.

Combining equation (32) with equation (33) - removing time index for briefness - it is possible to express the spread, $s(\bar{\omega})=\frac{\lambda(\bar{\omega})}{\Psi(\bar{\omega})}$ where $\Psi(\bar{\omega})=\lambda(\bar{\omega})[\Gamma(\bar{\omega})-\mu G(\bar{\omega})]+(1-\Gamma(\bar{\omega}))$, as a function of the leverage ratio, $k(\bar{\omega})=\frac{\Psi(\bar{\omega})}{(1-\Gamma(\bar{\omega}))}$,

$$
s=\frac{\lambda(\bar{\omega})}{1-\Gamma(\bar{\omega})} k^{-1}
$$

The following equations show how to compute the elasticity of the external finance premium 
with respect to the leverage, $\varkappa$ :

$$
\begin{gathered}
\varkappa=-\frac{d \log s}{d \log k} \\
\frac{d \log s}{d \bar{\omega}}=\frac{d[\log \lambda(\bar{\omega})-\log \Psi(\bar{\omega})]}{d \bar{\omega}} \\
=\frac{1}{\lambda(\bar{\omega})} \lambda^{\prime}(\bar{\omega})-\frac{1}{\Psi(\bar{\omega})} \Psi^{\prime}(\bar{\omega}) \\
\frac{d \log k}{d \bar{\omega}}=\frac{d[\log \Psi(\bar{\omega})-\log (1-\Gamma(\bar{\omega}))]}{d \bar{\omega}} \\
=\frac{1}{\Psi(\bar{\omega})} \Psi^{\prime}(\bar{\omega})+\frac{1}{(1-\Gamma(\bar{\omega}))} \Gamma^{\prime}(\bar{\omega})
\end{gathered}
$$

Hence:

$$
\varkappa=-\frac{\frac{\lambda^{\prime}(\bar{\omega})}{\lambda(\bar{\omega})}-\frac{\Psi^{\prime}(\bar{\omega})}{\Psi(\bar{\omega})}}{\frac{\Psi^{\prime}(\bar{\omega})}{\Psi(\bar{\omega})}+\frac{\Gamma^{\prime}(\bar{\omega})}{(1-\Gamma(\bar{\omega}))}}
$$

where

$$
\begin{gathered}
\lambda^{\prime}(\bar{\omega})=\frac{\mu\left[\Gamma^{\prime} G^{\prime \prime}-\Gamma^{\prime \prime} G^{\prime}\right]}{\left[\Gamma^{\prime}-\mu G^{\prime}\right]^{2}} \\
\Psi^{\prime}(\bar{\omega})=\lambda^{\prime}[\Gamma-\mu G]+\lambda\left[\Gamma^{\prime}-\mu G^{\prime}\right]-\Gamma^{\prime}
\end{gathered}
$$

To solve for $\bar{\omega}$, assume that $\omega$ is distributed log-normally: $\ln (\omega) \sim N\left(-0.5 \sigma^{2}, \sigma^{2}\right)$.

The optimality conditions of profit maximization yield the following demands for households and entrepreneurial labor:

$$
\begin{gathered}
\frac{W_{t}}{P_{t}}=[\Omega(1-\alpha)] M C_{t} \frac{Y_{t}}{L_{t}^{h}} \\
W_{t}^{e}=(1-\Omega)(1-\alpha) M C_{t} Y_{t}
\end{gathered}
$$

where $M C_{t+1}$ represents the real marginal cost, and $W_{t}^{e}$ is entrepreneurial wage.

Following the procedure described by Meier and Muller (2006), it is possible to find the threshold value $\bar{\omega}$ which solves the financial contract. Under steady state the entrepreneurs' optimality conditions (5) and (4) can be expressed as

$$
\frac{\alpha}{M} \frac{Y}{K}=R^{k}-(1-\delta)
$$

where $M$ is the gross steady state mark-up, equal to the inverse of the marginal cost. Under steady state the net worth accumulation reads as follows:

$$
\frac{N}{K}=\frac{\theta}{\gamma} \frac{V}{K}+\frac{(1-\Omega)(1-\alpha)}{\gamma M} \frac{Y}{K}
$$


where $\theta$ is the survival rate and $\Omega$ is the share of households labor. Entrepreneurial equity is

$$
V=[1-\mu G(\omega)] R^{k} Q K-R(Q K-N)
$$

Substituting for equation (27) the ratio of entrepreneurial equity to capital can be written as

$$
\frac{V}{K}=(1-\Gamma(\bar{\omega})) Q R^{k}
$$

Combining previous equation yields:

$$
\frac{N}{K}-\frac{\theta}{\gamma}(1-\Gamma(\bar{\omega})) R^{k}=\frac{(1-\Omega)(1-\alpha)}{\gamma \alpha}\left[R^{k}-(1-\delta)\right]
$$

Dividing by $R=\Pi / \beta \gamma^{-\sigma^{c}}$ yields

$$
\frac{\beta \gamma^{-\sigma^{c}}}{k(\bar{\omega}) \Pi}-\frac{\theta}{\gamma}[1-\Gamma(\bar{\omega})] s(\bar{\omega})=\frac{(1-\Omega)(1-\alpha)}{\gamma \alpha}\left[s(\bar{\omega})-\frac{\beta \gamma^{-\sigma^{c}}}{\Pi}(1-\delta)\right]
$$

Hence $\bar{\omega}$, which determines the leverage, the spread and the business failure rate, is a function of the following parameters: $\alpha, \beta, \gamma, \delta, \theta, \mu, \Pi, \sigma^{c}, \sigma^{2}, \Omega$.

\section{B.2 Model summary: linearised equations}

Note that the deterministic growth rate driven by technological progress is represented by $\gamma$, similarly to Smets and Wouters (2007), and $Z_{t}^{k}=\Psi^{\prime}\left(U_{t}\right)$. Lower case variables represent detrended variables, variables without time subscripts denote steady-state values and the hat denotes variables loglinearized around their steady state balanced growth path.

$$
\begin{gathered}
\hat{c}_{t}=\frac{h / \gamma}{1+h / \gamma} \hat{c}_{t-1}+\frac{1}{1+h / \gamma} \hat{c}_{t+1}-\frac{1-h / \gamma}{\sigma^{c}(1+h / \gamma)}\left(\hat{R}_{t}^{n}-E_{t}\left[\hat{\Pi}_{t+1}\right]\right) \\
-\frac{\left(\sigma^{c}-1\right)\left(w^{h} L^{h} / C\right)}{\sigma^{c}(1+h / \gamma)}\left(E_{t}\left[\hat{L}_{t+1}^{h}\right]-\hat{L}_{t}^{h}\right) \\
\hat{w}_{t}=\frac{\beta \gamma^{1-\sigma^{c}}}{\left(1+\beta \gamma^{\left.1-\sigma^{c}\right)}\right.} E_{t}\left[\hat{w}_{t+1}\right]+\frac{1}{\left(1+\beta \gamma^{1-\sigma^{c}}\right)} \hat{w}_{t-1}+\frac{\beta \gamma^{1-\sigma^{c}}}{\left(1+\beta \gamma^{1-\sigma^{c}}\right)} E_{t}\left[\hat{\Pi}_{t+1}\right] \\
-\frac{\left(1+\beta \gamma^{1-\sigma^{c}} \sigma_{w i}\right)}{\left(1+\beta \gamma^{1-\sigma^{c}}\right)} \hat{\Pi}_{t}+\frac{\sigma \sigma_{w i}}{\left(1+\beta \gamma^{1-\sigma^{c}}\right)} \hat{\Pi}_{t-1}+\frac{1}{(1+\beta) \sigma_{w}} \frac{\left(1-\beta \gamma^{1-\sigma^{c}} \sigma_{w}\right)\left(1-\sigma_{w}\right)}{\left(\bar{\mu}^{w}-1\right) \varepsilon^{w}+1} \\
{\left[\sigma^{\ell} \hat{L}_{t}^{h}+\frac{1}{1-h / \gamma} \hat{c}_{t}-\frac{h / \gamma}{1-h / \gamma} \hat{c}_{t-1}-\hat{w}_{t}\right]+u_{t}^{w}} \\
\hat{m}_{t}=\hat{A}_{t}-\alpha \hat{Z}_{t}^{k}-(1-\alpha) \hat{w}_{t}+[\Omega(1-\alpha)-(1-\alpha)] \hat{L}_{t}^{h}
\end{gathered}
$$




$$
\begin{aligned}
& \hat{\Pi}_{t}=\frac{\sigma_{p i}}{1+\sigma_{p i} \beta \gamma^{1-\sigma^{c}}} \hat{\Pi}_{t-1}+\frac{\beta \gamma^{1-\sigma^{c}}}{1+\sigma_{p i} \beta \gamma^{1-\sigma^{c}}} E_{t}\left[\hat{\Pi}_{t+1}\right]-\frac{1}{1+\sigma_{p i} \beta \gamma^{1-\sigma^{c}}} \\
& \frac{\left(1-\beta \gamma^{1-\sigma^{c}} \sigma_{p}\right)\left(1-\sigma_{p}\right)}{\sigma_{p}\left((\bar{\mu}-1) \varepsilon^{p}+1\right)} \hat{m}_{t}+u_{t}^{p} \\
& \hat{y}_{t}=\hat{A}_{t}+\alpha\left(\hat{k}_{t}+\hat{U}_{t}\right)+(1-\alpha) \hat{L}_{t} \\
& \hat{L}_{t}=\Omega \hat{L}_{t}^{h} \\
& \hat{Z}_{t}^{k}=\frac{\zeta}{1-\zeta} \hat{U}_{t} \\
& \hat{w}_{t}^{e}=\hat{y}_{t}-\hat{m}_{t} \\
& \hat{R}_{t}^{k}=\frac{Z^{k}}{R^{k}} \hat{Z}_{t}^{k}+\frac{(1-\delta)}{R^{k}} \hat{Q}_{t}-\hat{Q}_{t-1} \\
& \hat{w}_{t}=\hat{Z}_{t}^{k}-\hat{L}_{t}^{h}+\hat{k}_{t}+\hat{U}_{t} \\
& \hat{R}_{t+1}^{k}-\hat{R}_{t}=\varkappa\left(\hat{Q}_{t}+\hat{k}_{t+1}-\hat{n}_{t+1}\right)+\hat{b}_{t} \\
& \hat{R}_{t}=\hat{R}_{t}^{n}-\hat{\Pi}_{t+1} \\
& \hat{n}_{t+1}=\frac{\theta}{\gamma} \frac{V}{N} \hat{v}_{t}+\frac{W^{e}}{\gamma N} \hat{w}_{t}^{e}+e_{t}^{n} \\
& \frac{V}{N} \widehat{v}_{t}=[1-\mu G(\bar{\omega})] R_{t}^{k} \frac{K}{N} \hat{R}_{t}^{k}+\frac{K}{N}\left[(1-\mu G(\bar{\omega})) R^{k}-R\right]\left(\hat{Q}_{t-1}+\hat{k}_{t}\right)- \\
& -\frac{K}{N} \mu R^{k} G^{\prime}(\bar{\omega}) \bar{\omega} \hat{\bar{\omega}}_{t}+R\left(\frac{K}{N}-1\right) \hat{R}_{t-1}+R \hat{n}_{t} \\
& \hat{s}_{t}=[1-s[\Gamma(\bar{\omega})-\mu G(\bar{\omega})]]\left\{\frac{\Gamma^{\prime \prime}(\bar{\omega})}{\Gamma^{\prime}(\bar{\omega})}-\frac{\left[\Gamma^{\prime \prime}(\bar{\omega})-\mu G^{\prime \prime}(\bar{\omega})\right]}{\Gamma^{\prime}(\bar{\omega})-\mu G^{\prime}(\bar{\omega})}\right\} \bar{\omega} \hat{\bar{\omega}}_{t+1}
\end{aligned}
$$

where $s=\frac{R^{k}}{R}$.

$$
\begin{gathered}
\hat{c}_{t}^{e}=\hat{v}_{t} \\
\hat{k}_{t+1}=\delta\left(\hat{i}_{t}+\hat{x}_{t}\right)+\frac{(1-\delta)}{\gamma} \hat{k}_{t} \\
\hat{i}_{t}=\frac{1}{\xi \gamma^{2}\left(1+\beta \gamma^{1-\sigma^{c}}\right)} \hat{Q}_{t}+\frac{1}{\left(1+\beta \gamma^{1-\sigma^{c}}\right)} \hat{i}_{t-1}+\frac{\beta \gamma^{1-\sigma^{c}}}{\left(1+\beta \gamma^{1-\sigma^{c}}\right)} E_{t}\left[\hat{i}_{t+1}\right]+\hat{x}_{t} \\
\hat{y}_{t}=\frac{C}{Y} \hat{c}_{t}+\frac{C^{e}}{Y} \hat{c}_{t}^{e}+\frac{I}{Y} \hat{i}_{t}+\frac{G}{Y} g_{t}+Z^{k} \frac{K}{Y} \hat{U}_{t}+\mu G(\bar{\omega}) R^{k} \frac{K}{Y}\left(\hat{R}_{t}^{k}+\hat{Q}_{t-1}+\hat{k}_{t}\right)+\mu R^{k} \frac{K}{Y} G^{\prime}(\bar{\omega}) \bar{\omega} \hat{\bar{\omega}}_{t} \\
\hat{R}_{t}^{n}=\rho_{i} \hat{R}_{t-1}^{n}+\left(1-\rho_{i}\right)\left[\rho_{\pi} \hat{\Pi}_{t}+\rho_{y}\left(\hat{y}_{t}-\hat{y}_{t}^{*}\right)\right]+\rho_{\Delta y}\left[\left(\hat{y}_{t}-\hat{y}_{t}^{*}\right)-\left(\hat{y}_{t-1}-\hat{y}_{t-1}^{*}\right)\right]+e_{t}^{i}
\end{gathered}
$$

where $\hat{y}_{t}^{*}$ is the flexible output in an economy without nominal rigidities and markup shocks.

$$
\widehat{A}_{t}=\rho_{a} \widehat{A}_{t-1}+\varepsilon_{t}^{a}, \quad \varepsilon_{t}^{a} \sim N\left(0, \sigma_{a}\right)
$$




$$
\begin{gathered}
\widehat{b}_{t}=\rho_{b} \widehat{b}_{t-1}+\varepsilon_{t}^{b}, \quad \varepsilon_{t}^{b} \sim N\left(0, \sigma_{b}\right) \\
G_{t}=\rho_{g} G_{t-1}+\varepsilon_{t}^{g}+\rho_{g a} \varepsilon_{t}^{a}, \quad \varepsilon_{t}^{g} \sim N\left(0, \sigma_{g}\right) \\
e_{t}^{i}=\rho_{i} e_{t-1}^{i}+\varepsilon_{t}^{i}, \quad \varepsilon_{t}^{i} \sim N\left(0, \sigma_{i}\right) \\
e_{t}^{n}=\rho_{n} e_{t-1}^{n}+\varepsilon_{t}^{n}, \quad \varepsilon_{t}^{n} \sim N\left(0, \sigma_{n}\right) \\
\widehat{x}_{t}=\rho_{x} \widehat{x}_{t-1}+\varepsilon_{t}^{x}, \quad \varepsilon_{t}^{x} \sim N\left(0, \sigma_{x}\right) \\
u_{t}^{p}=\rho_{p} u_{t-1}^{p}+\varepsilon_{t}^{p}-\mu_{p} \varepsilon_{t-1}^{p}, \quad \varepsilon_{t}^{p} \sim N\left(0, \sigma_{p}\right) \\
u_{t}^{w}=\rho_{w} u_{t-1}^{w}+\varepsilon_{t}^{w}-\mu_{w} \varepsilon_{t-1}^{w}, \quad \varepsilon_{t}^{w} \sim N\left(0, \sigma_{w}\right)
\end{gathered}
$$

\section{Steady state effects of the deep financial parameters}

Figure 16 shows the sensitivity of the leverage ratio, the spread, and the elasticity of the external finance premium to the calibration of the monitoring costs, $\mu$, the volatility of the idiosyncratic shock, $\sigma$, and the survival rate, $\theta$, respectively - by changing one parameter at a time. This exercise highlights the effects of the deep financial parameters on the financial variables targeted under steady state. The calibration of the other parameters which determines the value of $\bar{\omega}$ is the same as in the sample 1984-2007, shown in Table $5 .^{17}$

When monitoring costs are reduced the economy tends to a model without financial frictions: the premium is reduced, entrepreneurs can be more leveraged under steady state, and the elasticity approaches zero - i.e. a model without asymmetric information. These charts make also it clear that the financial accelerator mechanism has nonlinear effects: for the given calibration of the other parameters, in this experiment firms are allowed to have a steady state leverage greater than 2 only for values of the monitoring costs lower than 0.04. Similar nonlinearities can be detected by looking at the effects on the steady state spread of a change in the monitoring costs.

A reduction in the volatility of the firm-specific shock yields effects analogous to the change in monitoring costs, as evident from the second row of Figure 16. The spread and the elasticity tend do decrease, while the optimal leverage in steady state is substantially higher, similarly to the analysis of Kamber and Thoenissen (2012).

A rise in the survival rate of firms increases net worth. This implies a reduction in the steady state leverage and lower levels of the spread. The elasticity follows a similar decreasing pattern, as shown in last chart of Figure 16.

Hence a reduction in either $\mu$ or $\sigma$ leads to a negative relationship between the spread and the leverage, while a reduction in the survival rate leads to a fall in both the leverage and the spread. Fernández and Gulan (2015) suggest that these patters can be explained in terms of demand and

\footnotetext{
${ }^{17}$ It is worth noting that, while the steady state common growth rate $\gamma$ barely affects the financial variables, the steady state inflation rate $\Pi$ has a considerable effects on the steady state spread. In particular, the lower the steady state inflation the higher the spread. This explains why the second sample - featuring lower monitoring costs and standard deviation of idiosyncratic uncertainty, and higher survival rate - is characterised by a higher steady state spread.
} 

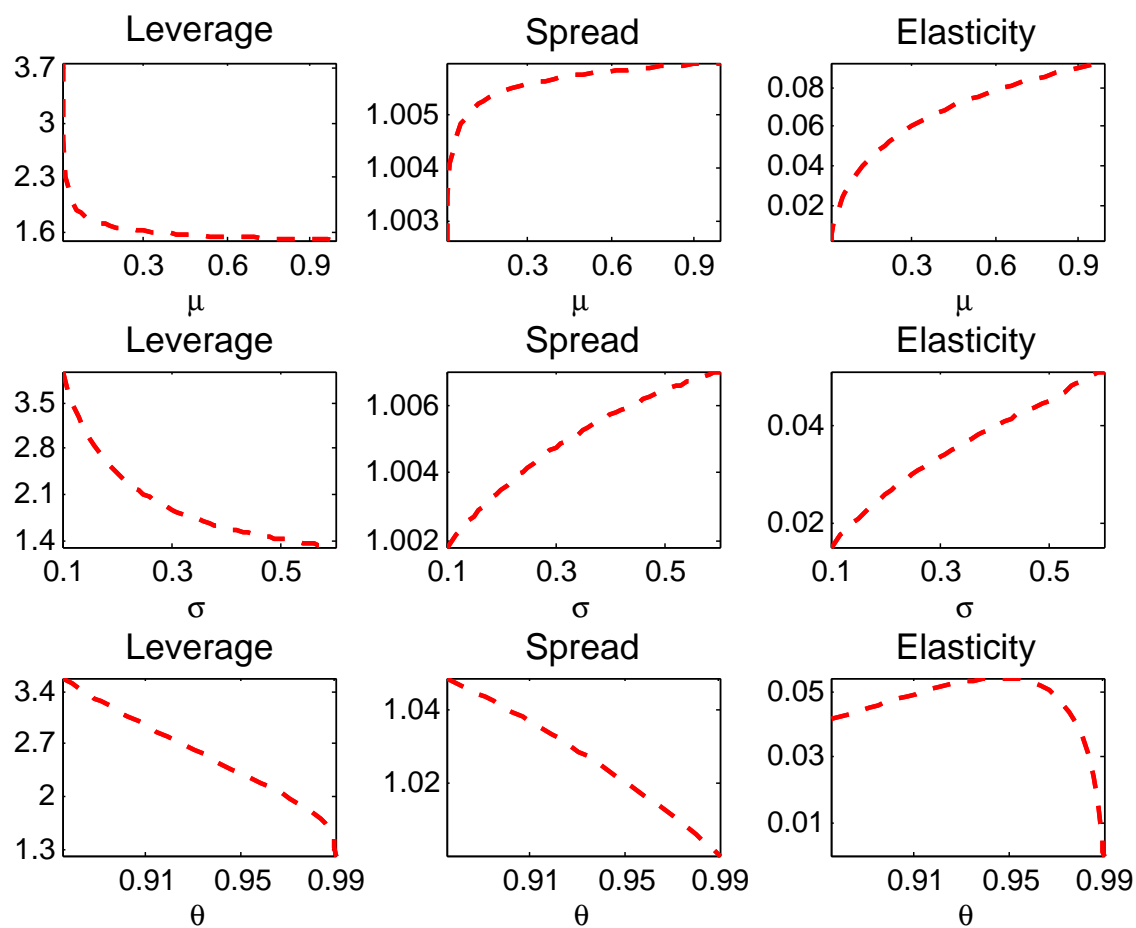

Figure 16: Steady state effects on leverage, spread and elasticity of the external finance premium with respect to the leverage position of firms of changing the deep financial parameters - monitoring costs, $\mu$, volatility of the idiosyncratic shock, $\sigma$, and the survival rate, $\theta$

supply of loans because the former is affected by a change in the survival rate and the latter by changes in the volatility and the monitoring costs.

\section{Data sources and transformations}

There are eight observables in the estimation. GDP, GDP deflator inflation, the federal funds rate, civilian population (CNP160V) and civilian employment (CE160V) are downloaded from the ALFRED database of the Federal Reserve Bank of St. Louis. Private consumption expenditures and fixed private investment are extracted from the NIPA Table 1.1.5 of the Bureau of Economic Analysis. Average weekly hours worked (PRS85006023) and compensation per hour (PRS85006103) are downloaded from the Bureau of Labor Statistics. The spread is measured as annualized Moody's seasoned Baa corporate bond yield spread over the 10-year Treasury note yield at constant maturity (see Del Negro and Schorfheide, 2013, among others).

Data are transformed as in Smets and Wouters (2007). In particular, GDP, consumption and investment are transformed in real per-capita terms by dividing their nominal values by the GDP deflator and the civilian population. Real wages are computed by dividing compensation per hour by the GDP deflator. The observable variables of GDP, consumption, investment and wages are expressed in first differences. Hours worked are multiplied by civilian employment, expressed in per capita terms and demeaned. The inflation rate is computed as a quarter-on-quarter difference of the 
log of the GDP deflator. The federal funds rate and the spread are expressed in quarterly terms and all the other variables are expressed as 100 times their logarithm. All series are seasonally adjusted by their sources.

The following set of measurement equations show the link between the observables in the dataset and the endogenous variables of the DSGE model:

$$
\left[\begin{array}{c}
\Delta Y_{t}^{o} \\
\Delta C_{t}^{o} \\
\Delta I_{t}^{o} \\
\Delta W_{t}^{o} \\
L_{t}^{o} \\
\pi_{t}^{o} \\
R_{t}^{n, o} \\
S_{t}^{o}
\end{array}\right]=\left[\begin{array}{c}
\gamma \\
\gamma \\
\gamma \\
\gamma \\
\bar{\ell} \\
\Pi \\
R^{n} \\
\bar{s}
\end{array}\right]+\left[\begin{array}{c}
\hat{y}_{t}-\hat{y}_{t-1} \\
\hat{c}_{t}-\hat{c}_{t-1} \\
\hat{i}_{t}-\hat{i}_{t-1} \\
\hat{w}_{t}-\hat{w}_{t-1} \\
\hat{L}_{t} \\
\hat{\Pi}_{t} \\
\hat{R}_{t}^{n} \\
\hat{S}_{t}^{n}
\end{array}\right]+\left[\begin{array}{l}
0 \\
0 \\
0 \\
0 \\
0 \\
0 \\
0
\end{array}\right],
$$

where variables on the left-hand side are the observables, $\gamma$ is the common quarterly trend growth rate of GDP, consumption, investment and wages; $\bar{\ell}$ is average hours worked; $\Pi$ is the average quarterly inflation rate; $R^{n}$ is the average quarterly nominal interest rate; and $\bar{s}$ is the average quarterly spread. A hat over a variable indicates the log-deviation from its own steady state.

In the robustness exercise in Appendix E.3 net worth of the corporate business sector is computed as in Table 2, i.e. as the difference between non-financial assets and credit market instruments (liabilities). It is transformed in real per-capita terms and the observable variable is expressed in first difference.

\section{E Sensitivity exercises for the estimation of the DSGE model}

This section illustrates a series of modifications in the baseline estimation of the DSGE model in order to analyse the robustness of the main results. Section E.1 shows the sensitivity of the counterfactual exercises to a longer dataset which includes the Great Recession, while Section E.2 carries out a similar analysis by looking at the effect of the other structural parameters on the slow recoveries. Section E.3 explores the robustness of the results when net worth of the corporate business sector is added as observable in the dataset.

\section{E.1 Including the Great Recession}

The most recent financial crisis has led to a revived interest in the role of deleveraging and financial factors in affecting the recovery (e.g. Ng and Wright, 2013). The counterfactual exercises presented in the paper does not include the Great Recession for potential distortionary effects on the estimates of the zero lower bound on the nominal interest rate. In this section we conduct the counterfactual exercises for a longer second sample, 1984Q1-2013Q1. The calibration of the sample-specific parameters is as follows: the quarterly growth rate of GDP, consumption, investment and wage, $\gamma$, is 


\begin{tabular}{lc|cc}
\hline & Baseline & \multicolumn{2}{|c}{ Counterfactuals } \\
\hline & & $\begin{array}{c}\text { Financial parameters } \\
\text { of sample 2 }\end{array}$ & $\begin{array}{c}\text { Structural and financial } \\
\text { parameters of sample 2 }\end{array}$ \\
Gample 1: 1965-1983 & & 3.31 & 1.16 \\
Investment & 3.80 & 6.06 & 1.46 \\
Consumption & 6.93 & 2.50 & 0.95 \\
\hline & 2.93 & Financial parameters & Structural and financial \\
Sample 2: 1984-2013 & & of sample 1 & parameters of sample 1 \\
GDP & 1.24 & 1.83 & 1.62 \\
Investment & -3.20 & -2.18 & -4.99 \\
Consumption & 1.41 & 1.62 & 1.81 \\
\hline
\end{tabular}

Table 11: Average 4-quarter growth rates after trough when sample 2 is 1984-2013

equal to 1.00334 , while the steady state inflation rate is 1.0059 , consistently with the dataset. The monitoring costs, the standard deviation of the idiosyncratic shock and the survival rate are equal to $0.103,0.325$ and 0.9808 respectively to target a leverage ratio of 1.83 , a spread of 228 basis points and a business failure rate of about four percent per year. Table 17 shows posterior estimates.

The results of this alternative exercise shown in Tables 11 are in line with those of the shorter sample. An economy featuring a higher leverage, spread and business failure rate recovers slower and vicevers a - but the role of financial factors per se is limited. When we simulate the outcomes of the pre- 84 shocks with the post- 84 parameters in place, the difference in growth rates after trough becomes larger, particularly for investment whose growth rate drops to 1.46. However, results should be interpreted cautiously due to the potential parameter bias due to the zero lower bound.

\section{E.2 The role of other parameters in affecting the speed of recovery}

Table 12 shows the effect of the other structural parameters in isolation in accounting for the slow recoveries. When we simulate the outcomes of the sample 1 shocks with the sample 2 parameters, monetary policy and price stickiness affect the speed of recovery of both GDP and investment, while other parameters - such as investment adjustment costs and capital utilisation - play a smaller role.

A similar exercise conducted for sample 2 shows that other structural parameters, such as investment adjustment costs, price and wage stickiness, barely affect the speed of recovery over the Great Moderation. Interestingly, if monetary policy would have been conducted as in the 1965-1983 period recoveries would have been even slower.

\section{E.3 Adding net worth of the corporate business sector as observable}

This section examines whether results are robust to a different estimation procedure. We use net worth of the corporate business sector as financial observable instead of the spread. ${ }^{18}$

Table 13 shows the outcomes of the pre-83Q4 shocks with the post-83Q4 financial parameters

\footnotetext{
${ }^{18}$ Table 18 in Appendix G shows the posteriors of the estimated parameters. We tried to estimate the deep financial parameters, but they were not identified - monitoring costs in particular. Hence, they are calibrated.
} 


\begin{tabular}{|c|c|c|c|c|c|c|}
\hline & \multirow[t]{2}{*}{ Baseline } & \multicolumn{5}{|c|}{ Counterfactuals } \\
\hline & & $\begin{array}{l}\text { Monet. policy } \\
\text { of sample } 2\end{array}$ & $\begin{array}{l}\text { Inv. adj. cost } \\
\text { of sample } 2\end{array}$ & $\begin{array}{l}\text { Capital util. } \\
\text { of sample } 2\end{array}$ & $\begin{array}{l}\text { Wage stick. } \\
\text { of sample } 2\end{array}$ & $\begin{array}{l}\text { Price stick. } \\
\text { of sample } 2\end{array}$ \\
\hline Sample 1: 1965-1983 & & & & & & \\
\hline GDP & 3.80 & 2.60 & 3.78 & 3.74 & 3.70 & 1.95 \\
\hline Investment & 6.93 & 5.79 & 7.06 & 6.85 & 6.72 & 3.21 \\
\hline Consumption & 2.93 & 1.80 & 2.83 & 2.89 & 2.86 & 1.70 \\
\hline Sample 2: 1984-2007 & & $\begin{array}{l}\text { Monet. policy } \\
\text { of sample } 1\end{array}$ & $\begin{array}{c}\text { Inv. adj. cost } \\
\text { of sample } 1\end{array}$ & $\begin{array}{l}\text { Capital util. } \\
\text { of sample } 1\end{array}$ & $\begin{array}{l}\text { Wage stick. } \\
\text { of sample } 1\end{array}$ & $\begin{array}{l}\text { Price stick. } \\
\text { of sample } 1\end{array}$ \\
\hline GDP & 1.12 & -2.19 & 0.99 & 1.19 & 1.12 & 0.89 \\
\hline Investment & -3.17 & -13.00 & -3.84 & -3.37 & -3.21 & -3.86 \\
\hline Consumption & 1.27 & -0.26 & 1.26 & 1.34 & 1.29 & 1.19 \\
\hline
\end{tabular}

Table 12: Average 4-quarter growth rates after trough

\begin{tabular}{clcc}
\hline & Simulated series & $\begin{array}{c}\text { 4-quarter growth } \\
\text { rate of GDP }\end{array}$ & $\begin{array}{c}\text { 4-quarter growth } \\
\text { rate of investment }\end{array}$ \\
\hline \hline $\begin{array}{c}\text { Sample 1: 1965-1983 } \\
\text { Baseline model }\end{array}$ & & 3.62 & 6.62 \\
\hline & Financial parameters from sample 2 & 3.59 & 6.14 \\
& Monetary policy from sample 2 & 2.66 & 5.40 \\
& Inv. adj. cost from sample 2 & 2.55 & 3.51 \\
& Capital utiliz. from sample 2 & 3.49 & 6.59 \\
Counterfactual models & Wage stickiness from sample 2 & 3.60 & 6.23 \\
& Price stickiness from sample 2 & 2.99 & 4.72 \\
& All structural and financial & & \\
& parameters from sample 2 & 1.56 & 1.73 \\
\hline
\end{tabular}

Table 13: Average 4-quarter growth rates after trough when the financial observable is net worth

in place. Financial parameters of sample 2 affect the growth rates of output and investment, which decrease. However, the difference in growth rates between the baseline model and the counterfactual one is not statistically significant. When taking into account all the structural and financial parameters, the speed of recovery of GDP and investment is slower similarly to the results shown in Table 7. These additional counterfactual experiments confirm that the financial conditions of the corporate business sector cannot provide an explanation on why recoveries have become slower since the 1990 s.

Turning to the role of shocks, Table 14 shows variance decomposition analysis of output growth, investment growth, inflation and the nominal interest rate in the estimated models. The wealth shock accounts for $14 \%$ of the variation in investment in the first sample, and for $17 \%$ of its variation in the second sample. TFP shock is the dominant source of output growth, while investment-specific technology and the risk premium shocks are the main driver of investment. Monetary policy shocks play a non-negligible role in affecting output fluctuations, while mark-up shocks are the dominant source of inflation variance. The nominal interest rate is mainly driven by the two financial shocks, the risk premium and the wealth shocks. Compared to Table 8, the risk premium shock plays a 


\begin{tabular}{|c|c|c|c|c|c|c|c|c|}
\hline & \multicolumn{8}{|c|}{ Structural shocks } \\
\hline & Wealth & $\begin{array}{c}\text { Risk } \\
\text { premium }\end{array}$ & $\begin{array}{c}\text { Gov. } \\
\text { spending }\end{array}$ & $\begin{array}{l}\text { Mon. } \\
\text { policy }\end{array}$ & $\begin{array}{l}\text { Invest. } \\
\text { specific }\end{array}$ & TFP & $\begin{array}{c}\text { Price } \\
\text { mark-up }\end{array}$ & $\begin{array}{c}\text { Wage } \\
\text { mark-up }\end{array}$ \\
\hline Output growth & $4.43 ; 7.47$ & $11.99 ; 12.54$ & $5.57 ; 8.96$ & $12.31 ; 10.52$ & $8.43 ; 14.43$ & $46.96 ; 25.48$ & $7.31 ; 16.39$ & $3.00 ; 4.20$ \\
\hline Investment growth & $14.33 ; 16.89$ & $29.93 ; 33.50$ & $0.07 ; 0.02$ & $5.60 ; 2.07$ & $28.11 ; 35.63$ & $13.55 ; 2.91$ & $5.90 ; 7.77$ & $2.52 ; 1.22$ \\
\hline Inflation & $37.13 ; 24.76$ & $17.66 ; 13.88$ & $2.87 ; 1.51$ & $1.16 ; 1.74$ & $14.08 ; 9.56$ & $11.61 ; 3.93$ & $10.60 ; 33.26$ & $4.89 ; 11.36$ \\
\hline Nominal interest rate & $35.92 ; 34.90$ & $23.50 ; 26.69$ & $2.60 ; 1.92$ & $5.76 ; 2.21$ & $18.60 ; 22.77$ & $8.06 ; 2.30$ & $2.68 ; 2.79$ & $2.87 ; 3.42$ \\
\hline
\end{tabular}

Table 14: Variance decomposition. The first number refers to the model estimated over the 19651983 sample while the second to the model estimated over the 1984-2007 sample

more prominent role in explaining business cycle fluctuations.

\section{F Allowing for nominal debt-contracts}

Bernanke et al. (1999) assume that debt contracts are concluded in real terms. This precludes the so-called Fisher effect: an unanticipated increase in inflation lowers the real debt burden of entrepreneurs and thus increases their net worth. As shown by Christensen and Dib (2008) and Christiano et al. (2010), the Fisher-effect generates further amplification in the case of monetary policy shocks. In the case of productivity shocks, instead, an attenuator effect is present. In fact, the countercyclical change in inflation affects the real cost of repaying existing debt, which pushes down net worth in case of expansionary shocks. Lower net worth increases the external finance premium, dampening the rise in the demand for capital.

This section investigates the robustness of the results to the presence of the Fisherian debtdeflation channel.

Similarly to Carrillo and Poilly (2013), let us define the nominal gross aggregate ex-post return on capital expenditures, $R_{t}^{k n}$, as

$$
E_{t}\left[R_{t+1}^{k n}\right]=E_{t}\left[\frac{Z_{t+1}^{k}+(1-\delta) Q_{t+1}}{Q_{t}} \pi_{t+1}\right]
$$

In case of nominal debt-contracts the optimal contracting problem can be written as:

$$
\begin{array}{ll}
\max _{K, \bar{\omega}} & \left(1-\Gamma\left(\bar{\omega}_{t+1}\right)\right) R_{t}^{k n} Q_{t} K_{t} \\
\text { s.t. } & {\left[\Gamma\left(\bar{\omega}_{t+1}\right)-\mu G\left(\bar{\omega}_{t+1}\right)\right] R_{t}^{k n} Q_{t} K_{t}=R_{t}^{n}\left(Q_{t} K_{t}-N_{t}\right)}
\end{array}
$$

Define $s^{n}=\frac{R^{k n}}{R^{n}}, k=\frac{Q K}{N}$, and $\lambda$ the Lagrange multiplier. The first order conditions are:

$$
\begin{aligned}
\bar{\omega} & : \quad \Gamma^{\prime}\left(\bar{\omega}_{t+1}\right)-\lambda\left[\Gamma^{\prime}\left(\bar{\omega}_{t+1}\right)-\mu G^{\prime}\left(\bar{\omega}_{t+1}\right)\right]=0 \\
k: & \left\{\left(1-\Gamma\left(\bar{\omega}_{t+1}\right)\right)+\lambda_{t}\left[\Gamma\left(\bar{\omega}_{t+1}\right)-\mu G\left(\bar{\omega}_{t+1}\right)\right]\right\} s_{t}^{n}-\lambda_{t}=0 \\
\lambda: & {[\Gamma(\bar{\omega})-\mu G(\bar{\omega})] s^{n} k-(k-1)=0 }
\end{aligned}
$$




\begin{tabular}{lc|cc}
\hline & Baseline & \multicolumn{2}{|c}{ Counterfactuals } \\
\hline & & $\begin{array}{c}\text { Financial parameters } \\
\text { of sample 2 }\end{array}$ & $\begin{array}{c}\text { Structural and financial } \\
\text { parameters of sample 2 }\end{array}$ \\
GDP & & 3.57 & 1.99 \\
Investment & 3.64 & 5.76 & 2.98 \\
Consumption & 6.26 & 2.85 & 1.69 \\
\hline & 2.92 & Financial parameters & Structural and financial \\
Sample 2: 1984-2007 & & of sample 1 & parameters of sample 1 \\
GDP & 1.13 & 1.27 & -0.56 \\
Investment & -3.20 & -2.40 & -5.35 \\
Consumption & 1.29 & 1.06 & -0.76 \\
\hline
\end{tabular}

Table 15: Average 4-quarter growth rates after trough in the model featuring nominal debt-contracts

The presence of nominal debt-contracts affects the following linearised equations:

$$
\begin{gathered}
\hat{R}_{t}^{k n}=\frac{Z^{k}}{R^{k}} \hat{Z}_{t}^{k}+\frac{(1-\delta)}{R^{k}} \hat{Q}_{t}-\hat{Q}_{t-1}+\pi_{t+1} \\
\hat{R}_{t+1}^{k n}-\hat{R}_{t}^{n}=\varkappa\left(\hat{Q}_{t}+\hat{k}_{t+1}-\hat{n}_{t+1}\right)+\hat{b}_{t} \\
\frac{V}{N} \widehat{v}_{t}=[1-\mu G(\bar{\omega})] R_{t}^{k n} \frac{K}{N} \hat{R}_{t}^{k n}+\frac{K}{N}\left[(1-\mu G(\bar{\omega})) R^{k n}-R^{n}\right]\left(\hat{Q}_{t-1}+\hat{k}_{t}\right)- \\
-\frac{K}{N} \mu R^{k n} G^{\prime}(\bar{\omega}) \bar{\omega} \hat{\bar{\omega}}_{t}+R^{n}\left(\frac{K}{N}-1\right) \hat{R}_{t-1}^{n}+R^{n} \hat{n}_{t}
\end{gathered}
$$

Table 15 shows the results of the counterfactual experiments under this alternative specification of the financial contract. In the first sample the speed of recovery decreases when calibrating the financial parameters to the values of those in sample 2. But the difference is small, in particular for output whose 4-quarter growth rate after trough is 3.64 in the baseline specification and 3.57 in the counterfactual experiment. Same results apply to the second sample: an economy featuring a lower leverage and a lower spread recovers faster. However, the role of financial parameters per se is minor. Overall, the presence of nominal debt-contracts replicates the results of the model featuring real debt-contracts, shown in Table 7 .

Results are robust also as far as variance decomposition analysis is concerned. Table 16 reports the role of shocks in affecting the business cycle. Similarly to Table 8, the TFP shock is the main driver of output fluctuations while wealth and investment-specific technology shocks account for the majority of movements in investment. Hence our results are robust when allowing for nominal debt-contracts.

\section{G Posterior estimates}

Table 17 reports posterior distributions of the model estimated over the sample 1984Q1-2013Q1. Table 18 shows the posterior estimates for the models featuring net worth of non-financial corporate 


\begin{tabular}{|c|c|c|c|c|c|c|c|c|}
\hline & \multicolumn{8}{|c|}{ Structural shocks } \\
\hline & Wealth & $\begin{array}{c}\text { Risk } \\
\text { premium }\end{array}$ & $\begin{array}{c}\text { Gov. } \\
\text { spending }\end{array}$ & $\begin{array}{l}\text { Mon. } \\
\text { policy }\end{array}$ & $\begin{array}{l}\text { Invest. } \\
\text { specific }\end{array}$ & TFP & $\begin{array}{c}\text { Price } \\
\text { mark-up }\end{array}$ & $\begin{array}{c}\text { Wage } \\
\text { mark-up }\end{array}$ \\
\hline Output growth & $8.25 ; 7.88$ & $0.31 ; 0.64$ & $8.89 ; 15.79$ & $10.25 ; 12.11$ & $12.66 ; 20.81$ & $54.52 ; 37.27$ & $3.36 ; 5.15$ & $1.75 ; 0.35$ \\
\hline Investment growth & $33.88 ; 27.75$ & $1.51 ; 2.76$ & $0.84 ; 0.08$ & $3.04 ; 3.75$ & $53.62 ; 62.73$ & $5.58 ; 1.71$ & $1.01 ; 0.52$ & $0.52 ; 0.70$ \\
\hline Inflation & $56.43 ; 19.16$ & $0.97 ; 0.41$ & $8.43 ; 1.16$ & $3.26 ; 1.92$ & $7.41 ; 1.70$ & $8.01 ; 1.87$ & $9.17 ; 59.70$ & $6.33 ; 14.07$ \\
\hline Nominal interest rate & $61.74 ; 52.34$ & $1.09 ; 2.66$ & $8.80 ; 5.40$ & $6.66 ; 4.61$ & $9.96 ; 20.04$ & $4.87 ; 3.86$ & $2.29 ; 2.53$ & $4.59 ; 8.56$ \\
\hline
\end{tabular}

Table 16: Variance decomposition in the model featuring nominal debt-contracts. The first number refers to the model estimated over the 1965-1983 sample while the second to the model estimated over the 1984-2007 sample

sector as observable variable. Table 19 reports the posterior estimates for the two samples, 19651983 and 1984-2007 in the model featuring nominal debt-contracts. Finally, Table 20 shows posterior distributions of the model estimated over the whole sample, 1965-2007. For each specification the posterior is obtained using the random walk Metropolis Hastings algorithm with two chains of 250,000 draws each. 


\begin{tabular}{|c|c|c|c|c|}
\hline & \multicolumn{3}{|c|}{ Prior distribution } & Posterior mean \\
\hline Parameters & Distr & Mode & St.Dev. & $1984-2013$ \\
\hline \multicolumn{5}{|l|}{ Structural } \\
\hline$\xi$, inv. adj. costs & Normal & 4 & 1.5 & $3.12[1.28,4.85]$ \\
\hline$\sigma^{\ell}$, elasticity of work & Normal & 2 & 0.25 & $2.26[1.90,2.63]$ \\
\hline$h$, habit parameter & Beta & 0.7 & 0.1 & $0.31[0.24,0.39]$ \\
\hline$\sigma_{p}$, Calvo prices & Beta & 0.5 & 0.1 & $0.85[0.78,0.95]$ \\
\hline$\sigma_{w}$, Calvo wages & Beta & 0.5 & 0.1 & $0.89[0.85,0.92]$ \\
\hline$\sigma_{p i}$, price indexation & Beta & 0.5 & 0.15 & $0.32[0.11,0.51]$ \\
\hline$\sigma_{w i}$, wage indexation & Beta & 0.5 & 0.15 & $0.36[0.14,0.56]$ \\
\hline$\zeta$, elasticity of capital util & Beta & 0.5 & 0.15 & $0.90[0.84,0.96]$ \\
\hline$\rho_{\pi}$, Taylor rule & Normal & 1.5 & 0.25 & $1.51[1.02,1.79]$ \\
\hline$\rho_{y}$, Taylor rule & Beta & 0.125 & 0.05 & $0.04[0.01,0.07]$ \\
\hline$\rho_{\Delta_{y}}$, Taylor rule - changes in $y$ & Normal & 0.2 & 0.05 & $0.28[0.23,0.33]$ \\
\hline$\rho_{i}$, Taylor rule smoothing & Beta & 0.75 & 0.1 & $0.76[0.71,0.80]$ \\
\hline $\bar{\ell}$, steady state hours worked & Normal & 0 & 2 & $-0.17[-1.89,1.48]$ \\
\hline $\bar{s}$, steady state spread & Normal & 0.50 & 0.1 & $0.47[0.32,0.64]$ \\
\hline \multicolumn{5}{|l|}{ Shocks } \\
\hline$\rho_{a}$, per. of tech shock & Beta & 0.5 & 0.2 & $0.99[0.98,1.00]$ \\
\hline$\rho_{b}$, per. of risk premium shock & Beta & 0.5 & 0.2 & $0.95[0.93,0.98]$ \\
\hline$\rho_{g}$, per. of gov shock & Beta & 0.5 & 0.2 & $0.93[0.90,0.95]$ \\
\hline$\rho_{x}$, per. of investment shock & Beta & 0.5 & 0.2 & $0.71[0.63,0.79]$ \\
\hline$\rho_{i}$, per. of monetary shock & Beta & 0.5 & 0.2 & $0.32[0.23,0.41]$ \\
\hline$\rho_{p}$, per. of price mark-up shock & Beta & 0.5 & 0.2 & $0.87[0.78,0.96]$ \\
\hline$\rho_{w}$, per. of wage mark-up shock & Beta & 0.5 & 0.2 & $0.58[0.30,0.90]$ \\
\hline$\rho_{n}$, per. of wealth shock & Beta & 0.5 & 0.2 & $0.99[0.98,1.00]$ \\
\hline$\mu_{p}, \mathrm{MA}$ - price mark-up shock & Beta & 0.5 & 0.2 & $0.94[0.89,1.00]$ \\
\hline$\mu_{w}, \mathrm{MA}$ - wage mark-up shock & Beta & 0.5 & 0.2 & $0.88[0.82,0.95]$ \\
\hline$\rho_{g a}$, per. of gov to tech shock & Beta & 0.5 & 0.25 & $0.46[0.34,0.57]$ \\
\hline$\sigma_{a}$, std of tech shock & IG & 0.1 & 2 & $0.50[0.45,0.55]$ \\
\hline$\sigma_{b}$, std of risk premium shock & IG & 0.1 & 2 & $0.09[0.08,0.10]$ \\
\hline$\sigma_{g}$, std of gov shock & IG & 0.1 & 2 & $0.39[0.34,0.43]$ \\
\hline$\sigma_{x}$, std of investment shock & IG & 0.1 & 2 & $0.49[0.37,0.60]$ \\
\hline$\sigma_{i}$, std of monetary shock & IG & 0.1 & 2 & $0.14[0.12,0.16]$ \\
\hline$\sigma_{p}$, std of price mark-up shock & IG & 0.1 & 2 & $0.17[0.14,0.21]$ \\
\hline$\sigma_{w}$, std of wage mark-up shock & IG & 0.1 & 2 & $0.45[0.39,0.50]$ \\
\hline$\sigma_{n}$, std of wealth shock & IG & 0.1 & 2 & $0.20[0.16,0.24]$ \\
\hline
\end{tabular}

Table 17: Prior and posterior distributions in the sample 1984Q1-2013Q1 


\begin{tabular}{|c|c|c|c|c|c|}
\hline \multirow[b]{2}{*}{ Parameters } & \multicolumn{3}{|c|}{ Prior distribution } & \multirow{2}{*}{$\begin{array}{c}\text { Posterior mean } \\
1965-1983\end{array}$} & \multirow{2}{*}{$\begin{array}{c}\text { Posterior mean } \\
1984-2007\end{array}$} \\
\hline & Distr & Mode & St.Dev. & & \\
\hline \multicolumn{6}{|l|}{ Structural } \\
\hline$\xi$, inv. adj. costs & Normal & 4 & 1.5 & $1.43[0.52,2.40]$ & $5.20[3.24,7.15]$ \\
\hline$\sigma^{\ell}$, elasticity of work & Normal & 2 & 0.25 & $2.15[1.78,2.54]$ & $2.18[1.80,2.55]$ \\
\hline$h$, habit parameter & Beta & 0.7 & 0.1 & $0.43[0.35,0.52]$ & $0.39[0.31,0.47]$ \\
\hline$\sigma_{p}$, Calvo prices & Beta & 0.5 & 0.1 & $0.58[0.50,0.64]$ & $0.72[0.63,0.82]$ \\
\hline$\sigma_{w}$, Calvo wages & Beta & 0.5 & 0.1 & $0.91[0.88,0.94]$ & $0.92[0.89,0.94]$ \\
\hline$\sigma_{p i}$, price indexation & Beta & 0.5 & 0.15 & $0.26[0.11,0.40]$ & $0.27[0.10,0.43]$ \\
\hline$\sigma_{w i}$, wage indexation & Beta & 0.5 & 0.15 & $0.46[0.29,0.62]$ & $0.33[0.14,0.51]$ \\
\hline$\zeta$, elasticity of capital util & Beta & 0.5 & 0.15 & $0.59[0.41,0.77]$ & $0.78[0.66,0.91]$ \\
\hline$\rho_{\pi}$, Taylor rule & Normal & 1.5 & 0.25 & $1.45[1.32,1.57]$ & $1.82[1.62,2.03]$ \\
\hline$\rho_{y}$, Taylor rule & Normal & 0.125 & 0.05 & $0.02[0.00,0.03]$ & $0.03[0.01,0.04]$ \\
\hline$\rho_{\Delta_{y}}$, Taylor rule - changes in $y$ & Normal & 0.2 & 0.05 & $0.22[0.16,0.28]$ & $0.18[0.14,0.23]$ \\
\hline$\rho_{i}$, Taylor rule smoothing & Beta & 0.75 & 0.1 & $0.41[0.35,0.46]$ & $0.77[0.72,0.81]$ \\
\hline $\bar{\ell}$, steady state hours worked & Normal & 0 & 2 & $-0.50[-3.35,2.54]$ & $1.16[-1.65,4.01]$ \\
\hline $\bar{\gamma}_{n}$, growth rate of net worth & Normal & 0.33 & 0.1 & $0.40[0.25,0.56]$ & $0.34[0.20,0.48]$ \\
\hline \multicolumn{6}{|l|}{ Shocks } \\
\hline$\rho_{a}$, per. of tech shock & Beta & 0.5 & 0.2 & $0.97[0.96,0.99]$ & $0.96[0.94,0.98]$ \\
\hline$\rho_{b}$, per. of risk premium shock & Beta & 0.5 & 0.2 & $0.90[0.85,0.95]$ & $0.94[0.92,0.96]$ \\
\hline$\rho_{g}$, per. of gov shock & Beta & 0.5 & 0.2 & $0.97[0.96,0.99]$ & $0.98[0.96,0.99]$ \\
\hline$\rho_{x}$, per. of investment shock & Beta & 0.5 & 0.2 & $0.89[0.81,0.98]$ & $0.90[0.85,0.96]$ \\
\hline$\rho_{i}$, per. of monetary shock & Beta & 0.5 & 0.2 & $0.15[0.05,0.24]$ & $0.22[0.12,0.33]$ \\
\hline$\rho_{p}$, per. of price mark-up shock & Beta & 0.5 & 0.2 & $0.75[0.61,0.90]$ & $0.87[0.76,0.99]$ \\
\hline$\rho_{w}$, per. of wage mark-up shock & Beta & 0.5 & 0.2 & $0.54[0.33,0.77]$ & $0.50[0.29,0.71]$ \\
\hline$\rho_{n}$, per. of wealth shock & Beta & 0.5 & 0.2 & $0.99[0.98,1.00]$ & $0.99[0.98,1.00]$ \\
\hline$\mu_{p}, \mathrm{MA}$ - price mark-up shock & Beta & 0.5 & 0.2 & $0.49[0.25,0.71]$ & $0.60[0.39,0.81]$ \\
\hline$\mu_{w}, \mathrm{MA}$ - wage mark-up shock & Beta & 0.5 & 0.2 & $0.44[0.19,0.73]$ & $0.40[0.13,0.65]$ \\
\hline$\rho_{g a}$, per. of gov to tech shock & Beta & 0.5 & 0.25 & $0.59[0.48,0.71]$ & $0.49[0.36,0.62]$ \\
\hline$\sigma_{a}$, std of tech shock & IG & 0.1 & 2 & $0.79[0.68,0.90]$ & $0.46[0.40,0.52]$ \\
\hline$\sigma_{b}$, std of risk premium shock & IG & 0.1 & 2 & $0.25[0.18,0.32]$ & $0.26[0.21,0.31]$ \\
\hline$\sigma_{g}$, std of gov shock & IG & 0.1 & 2 & $0.48[0.42,0.55]$ & $0.36[0.31,0.40]$ \\
\hline$\sigma_{x}$, std of investment shock & IG & 0.1 & 2 & $0.61[0.41,0.82]$ & $0.27[0.21,0.33]$ \\
\hline$\sigma_{i}$, std of monetary shock & IG & 0.1 & 2 & $0.48[0.40,0.55]$ & $0.14[0.12,0.16]$ \\
\hline$\sigma_{p}$, std of price mark-up shock & IG & 0.1 & 2 & $0.19[0.14,0.23]$ & $0.11[0.08,0.14]$ \\
\hline$\sigma_{w}$, std of wage mark-up shock & IG & 0.1 & 2 & $0.20[0.15,0.24]$ & $0.28[0.23,0.34]$ \\
\hline$\sigma_{m}$, std of wealth shock & IG & 0.1 & 2 & $0.24[0.18,0.30]$ & $0.23[0.17,0.28]$ \\
\hline
\end{tabular}

Table 18: Prior and posterior distributions in the two samples of the model featuring net worth of non-financial corporate sector as observable variable 


\begin{tabular}{|c|c|c|c|c|c|}
\hline \multirow[b]{2}{*}{ Parameters } & \multicolumn{3}{|c|}{ Prior distribution } & \multirow{2}{*}{$\begin{array}{c}\text { Posterior mean } \\
1965-1983\end{array}$} & \multirow{2}{*}{$\begin{array}{c}\text { Posterior mean } \\
1984-2007\end{array}$} \\
\hline & Distr & Mode & St.Dev. & & \\
\hline \multicolumn{6}{|l|}{ Structural } \\
\hline$\xi$, inv. adj. costs & Normal & 4 & 1.5 & $4.42[2.71 ; 6.02]$ & $4.42[2.37 ; 6.30]$ \\
\hline$\sigma^{\ell}$, elasticity of work & Normal & 2 & 0.25 & $2.11[1.72 ; 2.50]$ & $2.39[2.03 ; 2.75]$ \\
\hline$h$, habit parameter & Beta & 0.7 & 0.1 & $0.44[0.36 ; 0.53]$ & $0.30[0.22 ; 0.38]$ \\
\hline$\sigma_{p}$, Calvo prices & Beta & 0.5 & 0.1 & $0.56[0.50 ; 0.60]$ & $0.86[0.79 ; 0.93]$ \\
\hline$\sigma_{w}$, Calvo wages & Beta & 0.5 & 0.1 & $0.87[0.84 ; 0.91]$ & $0.85[0.80 ; 0.91]$ \\
\hline$\sigma_{p i}$, price indexation & Beta & 0.5 & 0.15 & $0.25[0.10 ; 0.40]$ & $0.41[0.14 ; 0.68]$ \\
\hline$\sigma_{w i}$, wage indexation & Beta & 0.5 & 0.15 & $0.61[0.45 ; 0.77]$ & $0.33[0.13 ; 0.53]$ \\
\hline$\zeta$, elasticity of capital util & Beta & 0.5 & 0.15 & $0.74[0.60 ; 0.89]$ & $0.78[0.68 ; 0.90]$ \\
\hline$\rho_{\pi}$, Taylor rule & Normal & 1.5 & 0.25 & $1.37[1.22 ; 1.52]$ & $1.51[1.21 ; 1.79]$ \\
\hline$\rho_{y}$, Taylor rule & Normal & 0.125 & 0.05 & $0.03[0.01 ; 0.05]$ & $0.11[0.06 ; 0.16]$ \\
\hline$\rho_{\Delta_{y}}$, Taylor rule - changes in $y$ & Normal & 0.2 & 0.05 & $0.23[0.17 ; 0.30]$ & $0.28[0.23 ; 0.33]$ \\
\hline$\rho_{i}$, Taylor rule smoothing & Beta & 0.75 & 0.1 & $0.49[0.41 ; 0.56]$ & $0.80[0.76 ; 0.84]$ \\
\hline $\bar{\ell}$, steady state hours worked & Normal & 0 & 2 & $-1.62[-3.39 ; 0.21]$ & $0.92[-0.20 ; 2.03]$ \\
\hline $\bar{s}$, steady state spread & Normal & 0.50 & 0.1 & $0.53[0.37 ; 0.69]$ & $0.48[0.32 ; 0.64]$ \\
\hline \multicolumn{6}{|l|}{ Shocks } \\
\hline$\rho_{a}$, per. of tech shock & Beta & 0.5 & 0.2 & $0.99[0.97 ; 1.00]$ & $0.97[0.95 ; 1.00]$ \\
\hline$\rho_{b}$, per. of risk premium shock & Beta & 0.5 & 0.2 & $0.86[0.80 ; 0.92]$ & $0.92[0.88 ; 0.96]$ \\
\hline$\rho_{g}$, per. of gov shock & Beta & 0.5 & 0.2 & $0.95[0.93 ; 0.97]$ & $0.94[0.92 ; 0.96]$ \\
\hline$\rho_{x}$, per. of investment shock & Beta & 0.5 & 0.2 & $0.57[0.42 ; 0.72]$ & $0.59[0.50 ; 0.68]$ \\
\hline$\rho_{i}$, per. of monetary shock & Beta & 0.5 & 0.2 & $0.18[0.07 ; 0.30]$ & $0.19[0.09 ; 0.29]$ \\
\hline$\rho_{p}$, per. of price mark-up shock & Beta & 0.5 & 0.2 & $0.68[0.50 ; 0.86]$ & $0.67[0.40 ; 0.89]$ \\
\hline$\rho_{w}$, per. of wage mark-up shock & Beta & 0.5 & 0.2 & $0.48[0.23 ; 0.73]$ & $0.67[0.44 ; 0.92]$ \\
\hline$\rho_{n}$, per. of wealth shock & Beta & 0.5 & 0.2 & $0.97[0.94 ; 1.00]$ & $0.99[0.98 ; 1.00]$ \\
\hline$\mu_{p}, \mathrm{MA}-$ price mark-up shock & Beta & 0.5 & 0.2 & $0.45[0.21 ; 0.69]$ & $0.88[0.79 ; 0.98]$ \\
\hline$\mu_{w}, \mathrm{MA}$ - wage mark-up shock & Beta & 0.5 & 0.2 & $0.41[0.17 ; 0.67]$ & $0.92[0.87 ; 0.98]$ \\
\hline$\rho_{g a}$, per. of gov to tech shock & Beta & 0.5 & 0.25 & $0.54[0.42 ; 0.66]$ & $0.46[0.32 ; 0.59]$ \\
\hline$\sigma_{a}$, std of tech shock & $\mathrm{IG}$ & 0.1 & 2 & $0.82[0.71 ; 0.93]$ & $0.46[0.40 ; 0.51]$ \\
\hline$\sigma_{b}$, std of risk premium shock & IG & 0.1 & 2 & $0.10[0.09 ; 0.12]$ & $0.06[0.05 ; 0.07]$ \\
\hline$\sigma_{g}$, std of gov shock & IG & 0.1 & 2 & $0.51[0.44 ; 0.59]$ & $0.37[0.33 ; 0.42]$ \\
\hline$\sigma_{x}$, std of investment shock & IG & 0.1 & 2 & $0.71[0.53 ; 0.90]$ & $0.54[0.43 ; 0.64]$ \\
\hline$\sigma_{i}$, std of monetary shock & IG & 0.1 & 2 & $0.43[0.36 ; 0.49]$ & $0.13[0.11 ; 0.15]$ \\
\hline$\sigma_{p}$, std of price mark-up shock & IG & 0.1 & 2 & $0.19[0.15 ; 0.24]$ & $0.18[0.15 ; 0.21]$ \\
\hline$\sigma_{w}$, std of wage mark-up shock & IG & 0.1 & 2 & $0.20[0.16 ; 0.24]$ & $0.37[0.32 ; 0.44]$ \\
\hline$\sigma_{m}$, std of wealth shock & IG & 0.1 & 2 & $0.22[0.14 ; 0.29]$ & $0.17[0.13 ; 0.21]$ \\
\hline
\end{tabular}

Table 19: Prior and posterior distributions in the two samples of the model featuring nominal debt-contracts 


\begin{tabular}{|c|c|c|c|c|}
\hline & \multicolumn{3}{|c|}{ Prior distribution } & Posterior mean \\
\hline Parameters & Distr & Mode & St.Dev. & $1965-2007$ \\
\hline \multicolumn{5}{|l|}{ Structural } \\
\hline$\xi$, inv. adj. costs & Normal & 4 & 1.5 & $4.43[2.88 ; 5.99]$ \\
\hline$\sigma^{\ell}$, elasticity of work & Normal & 2 & 0.25 & $2.44[2.09 ; 2.79]$ \\
\hline$h$, habit parameter & Beta & 0.7 & 0.1 & $0.34[0.28 ; 0.41]$ \\
\hline$\sigma_{p}$, Calvo prices & Beta & 0.5 & 0.1 & $0.58[0.51 ; 0.64]$ \\
\hline$\sigma_{w}$, Calvo wages & Beta & 0.5 & 0.1 & $0.89[0.86 ; 0.92]$ \\
\hline$\sigma_{p i}$, price indexation & Beta & 0.5 & 0.15 & $0.24[0.10 ; 0.38]$ \\
\hline$\sigma_{w i}$, wage indexation & Beta & 0.5 & 0.15 & $0.42[0.18 ; 0.66]$ \\
\hline$\zeta$, elasticity of capital util & Beta & 0.5 & 0.15 & $0.70[0.55 ; 0.84]$ \\
\hline$\rho_{\pi}$, Taylor rule & Normal & 1.5 & 0.25 & $1.34[1.26 ; 1.43]$ \\
\hline$\rho_{y}$, Taylor rule & Beta & 0.125 & 0.05 & $0.03[0.01 ; 0.04]$ \\
\hline$\rho_{\Delta_{y}}$, Taylor rule - changes in $y$ & Normal & 0.2 & 0.05 & $0.33[0.28 ; 0.39]$ \\
\hline$\rho_{i}$, Taylor rule smoothing & Beta & 0.75 & 0.1 & $0.53[0.47 ; 0.59]$ \\
\hline $\bar{\ell}$, steady state hours worked & Normal & 0 & 2 & $0.54[-1.23 ; 2.28]$ \\
\hline $\bar{s}$, steady state spread & Normal & 0.50 & 0.1 & $0.50[0.34 ; 0.67]$ \\
\hline \multicolumn{5}{|l|}{ Shocks } \\
\hline$\rho_{a}$, per. of tech shock & Beta & 0.5 & 0.2 & $0.98[0.97 ; 0.99]$ \\
\hline$\rho_{b}$, per. of risk premium shock & Beta & 0.5 & 0.2 & $0.93[0.90 ; 0.97]$ \\
\hline$\rho_{g}$, per. of gov shock & Beta & 0.5 & 0.2 & $0.97[0.96 ; 0.98]$ \\
\hline$\rho_{x}$, per. of investment shock & Beta & 0.5 & 0.2 & $0.57[0.45 ; 0.68]$ \\
\hline$\rho_{i}$, per. of monetary shock & Beta & 0.5 & 0.2 & $0.13[0.05 ; 0.22]$ \\
\hline$\rho_{p}$, per. of price mark-up shock & Beta & 0.5 & 0.2 & $0.97[0.95 ; 0.99]$ \\
\hline$\rho_{w}$, per. of wage mark-up shock & Beta & 0.5 & 0.2 & $0.89[0.81 ; 0.96]$ \\
\hline$\rho_{n}$, per. of wealth shock & Beta & 0.5 & 0.2 & $0.99[0.99 ; 1.00]$ \\
\hline$\mu_{p}, \mathrm{MA}$ - price mark-up shock & Beta & 0.5 & 0.2 & $0.73[0.62 ; 0.85]$ \\
\hline$\mu_{w}, \mathrm{MA}$ - wage mark-up shock & Beta & 0.5 & 0.2 & $0.96[0.92 ; 0.99]$ \\
\hline$\rho_{g a}$, per. of gov to tech shock & Beta & 0.5 & 0.25 & $0.53[0.44 ; 0.62]$ \\
\hline$\sigma_{a}$, std of tech shock & $\overline{\mathrm{IG}}$ & 0.1 & 2 & $0.64[0.58 ; 0.69]$ \\
\hline$\sigma_{b}$, std of risk premium shock & IG & 0.1 & 2 & $0.08[0.07 ; 0.09]$ \\
\hline$\sigma_{g}$, std of gov shock & IG & 0.1 & 2 & $0.44[0.40 ; 0.48]$ \\
\hline$\sigma_{x}$, std of investment shock & IG & 0.1 & 2 & $0.56[0.46 ; 0.67]$ \\
\hline$\sigma_{i}$, std of monetary shock & $\mathrm{IG}$ & 0.1 & 2 & $0.33[0.30 ; 0.37]$ \\
\hline$\sigma_{p}$, std of price mark-up shock & IG & 0.1 & 2 & $0.16[0.14 ; 0.19]$ \\
\hline$\sigma_{w}$, std of wage mark-up shock & IG & 0.1 & 2 & $0.32[0.28 ; 0.35]$ \\
\hline$\sigma_{n}$, std of wealth shock & IG & 0.1 & 2 & $0.24[0.20 ; 0.27]$ \\
\hline
\end{tabular}

Table 20: Prior and posterior distributions in the sample 1965Q1-2007Q4 